\title{
Fermentative Production of
} L-2-Hydroxyglutarate by Engineered Corynebacterium glutamicum via Pathway Extension of L-Lysine Biosynthesis

\author{
Carina Prell, Arthur Burgardt, Florian Meyer and Volker F. Wendisch* \\ Genetics of Prokaryotes, Faculty of Biology, Center for Biotechnology (CeBiTec), Bielefeld University, Bielefeld, Germany
}

OPEN ACCESS

Edited by:

Yi-Rui Wu,

Shantou University, China

Reviewed by:

Si Jae Park,

Ewha Womans University,

South Korea

Liang Quanfeng,

Shandong University, China

Robert Bertrand,

University of California, Berkeley,

United States

*Correspondence:

Volker F. Wendisch

volker.wendisch@uni-bielefeld.de

Specialty section:

This article was submitted to

Industrial Biotechnology,

a section of the journal

Frontiers in Bioengineering and

Biotechnology

Received: 17 November 2020

Accepted: 24 December 2020

Published: 27 January 2021

Citation:

Prell C, Burgardt A, Meyer F and Wendisch VF (2021) Fermentative Production of L-2-Hydroxyglutarate by

Engineered Corynebacterium glutamicum via Pathway Extension of L-Lysine Biosynthesis.

Front. Bioeng. Biotechnol. 8:630476.

doi: 10.3389/fbioe.2020.630476
L-2-hydroxyglutarate ( $\mathrm{L}-2 \mathrm{HG})$ is a trifunctional building block and highly attractive for the chemical and pharmaceutical industries. The natural L-lysine biosynthesis pathway of the amino acid producer Corynebacterium glutamicum was extended for the fermentative production of L-2HG. Since L-2HG is not native to the metabolism of C. glutamicum metabolic engineering of a genome-streamlined L-lysine overproducing strain was required to enable the conversion of L-lysine to $L-2 H G$ in a six-step synthetic pathway. To this end, L-lysine decarboxylase was cascaded with two transamination reactions, two $N A D(P)$-dependent oxidation reactions and the terminal 2-oxoglutarate-dependent glutarate hydroxylase. Of three sources for glutarate hydroxylase the metalloenzyme CsiD from Pseudomonas putida supported L-2HG production to the highest titers. Genetic experiments suggested a role of succinate exporter SucE for export of L-2HG and improving expression of its gene by chromosomal exchange of its native promoter improved L-2HG production. The availability of $\mathrm{Fe}^{2+}$ as cofactor of CsiD was identified as a major bottleneck in the conversion of glutarate to $L-2 H G$. As consequence of strain engineering and media adaptation product titers of $34 \pm 0 \mathrm{mM}$ were obtained in a microcultivation system. The glucose-based process was stable in $2 \mathrm{~L}$ bioreactor cultivations and a $\mathrm{L}-2 \mathrm{HG}$ titer of $3.5 \mathrm{~g} \mathrm{~L}^{-1}$ was obtained at the higher of two tested aeration levels. Production of L-2HG from a sidestream of the starch industry as renewable substrate was demonstrated. To the best of our knowledge, this study is the first description of fermentative production of L-2HG, a monomeric precursor used in electrochromic polyamides, to cross-link polyamides or to increase their biodegradability.

Keywords: C. glutamicum, L-2-hydroxyglutarate, metabolic engineering, glutarate hydroxylase, wheat sidestream concentrate, bioreactor

\section{INTRODUCTION}

L-2-hydroxyglutarate (L-2HG) can be obtained by hydroxylation of the $\mathrm{C}_{5}$-dicarboxylic acid glutarate at the $\alpha$-carbon position. Glutarate is known to be a demanded building block for the production of biopolymers, like aliphatic polyamide 6,5 which is mainly used in the construction industry (Navarro et al., 1997). Carbon chain length and functional groups of the monomers 
are important for the performance of the biopolymer with respect to physical and chemical properties. In the case of $\mathrm{L}-2 \mathrm{HG}$, the additional hydroxyl group provides greater versatility for further chemical modification with the potential to alter the properties of the resulting polymer. Furthermore, incorporation of hydroxylated monomers enhances the biodegradability of the polyamide (Varela and Orgueira, 2000). Production of L-2HG by microbial fermentation would provide the chemical industry with an environmentally friendly building block for polyamides and polyesters. The addition of functionalities on polyester backbones (hydroxyl, carboxyl, allyl, azido, and acetylene groups) facilitates covalent post-polymerization modification. In 2017, it was shown that the enantiomer D-2-hydroxyglutarate (D-2HG) can be used as a functionalized building block for a polyester after cyclization to an allyl containing lactide (Nan and Feher, 2017). Also, it was demonstrated that electrochromic polyamides with functional hydroxyl groups for homogeneous hybrid films can be produced. The repeating units of hydroxysuccinate in the polymer backbone provided reaction sites for organic-inorganic bonding resulting in homogeneous and transparent hybrid films (Pan et al., 2018).

In medicine, L-2HG is used as a diagnostic biomarker for the characterization of various cancer types (Shim et al., 2014). Under oxygen limitation, L-2HG accumulates as metabolic intermediate in healthy as well as in malignant animal cells (Shim et al., 2014; Oldham et al., 2015; Shelar et al., 2018) facilitating a physiological adaption to hypoxic stress. The accumulation of $\mathrm{L}-$ $2 \mathrm{HG}$ is triggered by increasing concentrations of 2-oxoglutarate (2-OG), which is caused by tricarboxylic acid cycle dysfunction and increased mitochondrial reducing potential. As consequence, the increased cellular L-2HG concentrations lead to inhibition of the electron transport and glycolysis compensating the effects of mitochondrial reductive stress induced by hypoxia (Oldham et al., 2015). The stereospecific reduction of 2-oxoglutarate to $\mathrm{L}-2 \mathrm{HG}$ is catalyzed by lactate dehydrogenase (LDH) and malate dehydrogenase $(\mathrm{MDH})$ under hypoxic stress conditions (Intlekofer et al., 2017). In contrast, the formation of its enantiomer D-2-hydroxyglutarate (D-2HG) is catalyzed by a mutated version of isocitrate dehydrogenase 1 or 2 (IDH1/2) contributing to the pathogenesis of cancer, whereas L-2HG biosynthesis does neither involve IDH1 nor IDH2. Albeit both enantiomers of 2-hydroxyglutarate display an inhibitory effect on 2-oxoglutarate-dependent enzymes involved in diverse biologic processes (Chowdhury et al., 2011; Xu et al., 2011), their stereospecific biosynthesis differs. Thus, bio-based routes enable stereospecific synthesis of either D-2HG or L-2HG, which is preferred over chemically synthesized racemic D,L-2HG. Beyond the occurrence as a product of cellular redox stress, L-2HG also plays a role in plants and eukaryotic cells as part of the mitochondrial metabolic repair mechanism (Hüdig et al., 2015). A side reaction of $\mathrm{MDH}$ yields small concentrations of L-2HG by reduction of 2-oxoglutarate. The mitochondrial FAD-containing oxidase L-2-hydroxyglutarate dehydrogenase (L2HGDH, EC 1.1.5.13) oxidizes $\mathrm{L}-2 \mathrm{HG}$ and the electrons produced in the reaction are transferred to the mitochondrial electron transport chain through the electron transfer protein (ETF) (Wanders et al., 1997; Rzem et al., 2004). An enzyme homologous to L2HGDH was also described in the model organism Escherichia coli (Knorr et al., 2018).

In bacteria, L-2HG mainly accumulates under carbon starvation conditions (Marschall et al., 1998; Metzner et al., 2004; Knorr et al., 2018). It is also an intermediate of the L-lysine degradation pathway in Pseudomonadaceae (Zhang et al., 2018; Thompson et al., 2019). Glutarate is the direct precursor of L-2HG. Hydroxylation of glutarate to $\mathrm{L}-2 \mathrm{HG}$ is catalyzed by a highly regio- and stereospecific $\mathrm{Fe}(\mathrm{II}) / 2$ oxoglutarate-dependent dioxygenase CsiD (EC 1.14.11.64, also named glutarate hydroxylase) (Hibi and Ogawa, 2014). The coproduct succinate is metabolized via the TCA-cycle. Since L2-hydroxyglutarate oxidase ( $\mathrm{LghO})$ regenerates 2-oxoglutarate by oxidation of L-2HG (Knorr et al., 2018; Herr et al., 2019), the combined activities of CsiD and LghO convert the C5dicarboxylic acid glutarate to the C4-dicarboxylic acid succinate. Thus, the absence of LghO is required for overproduction of L-2HG from glutarate.

Glutarate can be derived from L-lysine by four pathways that converge to 5AVA, which is converted to glutarate by GABA/5AVA aminotransferase (GabT) and the succinate/glutarate semialdehyde dehydrogenase (GabD). The first pathway from L-lysine to 5AVA employs L-lysine- $\alpha$ oxidase (RaiP) from Scomber japonicus that catalyzes oxidative desamination of L-lysine using molecular oxygen followed by spontaneous decarboxylation (Cheng et al., 2020). The second pathway to 5AVA combines oxidative decarboxylation by L-lysine monooxygenase using molecular oxygen followed by desamidation by $\gamma$-aminovaleramidase from $P$. putida (Adkins et al., 2013). The third pathway is based on L-lysine decarboxylase from E. coli, putrescine oxidase $\mathrm{PuO}$ from Rhodococcus qingshengii and the $\gamma$-aminobutyraldehyde dehydrogenase from E. coli that catalyze decarboxylation, oxidative deamination using molecular oxygen and NADdependent oxidation (Haupka et al., 2020). The fourth pathway does not require molecular oxygen as it cascades L-lysine decarboxylase, 2-oxoglurate-dependent putrescine/cadaverine transaminase PatA, and NAD-dependent $\gamma$ - aminobutyraldehyde dehydrogenase PatD from E. coli (Jorge et al., 2017). The pathway combinations for LdcC-PuO-PatD-GabT-GabD and LdcC-PatAPatD-GabT-GabD couple conversion of lysine to glutarate in one or two transaminase reactions, respectively, that generate glutamate from 2-oxoglutarate. This coupling enabled flux enforcement, i.e., growth requires production of glutarate, which was achieved by deletion of $g d h$, the gene for the major ammonium assimilating enzyme L-glutamic acid dehydrogenase (Pérez-García et al., 2018; Haupka et al., 2020).

Since biosynthesis of L-2HG from glutarate requires molecular oxygen, glutarate biosynthesis from L-lysine by a pathway independent of molecular oxygen was extended by glutarate hydroxylase. The pathways RaiP-GabT-GabD, DavA-DavB-GabT-GabD, and LdcC-PuO-PatD-GabT-GabD involve oxygenases (RaiP, DavA, and $\mathrm{PuO}$, respectively), whereas the pathway LdcC-PatA-PatD-GabT-GabD does not contain an enzyme using molecular oxygen as substrate (Jorge et al., 2017). To construct the six-step cascade LdcC-PatA-PatD-GabTGabD-CsiD (Figure 1), CsiD enzymes from E. coli MG1655, 


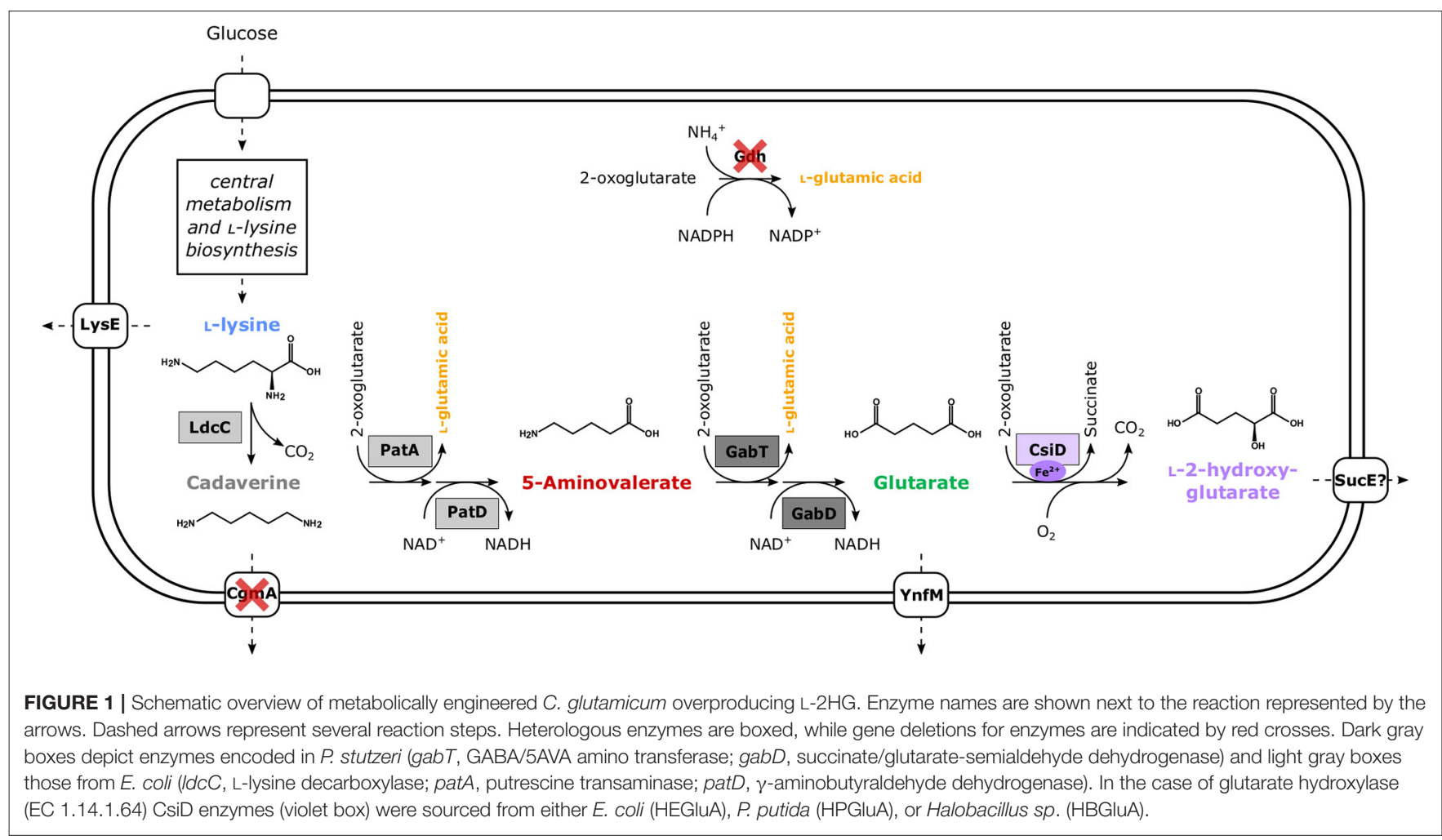

P. putida KT2440 and Halobacillus sp. BA-2008 were tested since inspection of the genome sequence of C. glutamicum did not indicate that a CsiD homolog is encoded. The absence of LhgO from the C. glutamicum genome was considered beneficial since it indicated that L-2HG may not be degraded. This and the fact that we previously established efficient glutarate production employing the LdcC-PatA-PatD-GabT-GabD pathway provided an ideal starting point to establish fermentative production of L-2HG from renewable resources. This concept may be transferred to fermentative production of the stereoisomer D-2HG by extending the glutarate pathway with enzymes for conversion of glutarate to D-2HG.

\section{MATERIALS AND METHODS}

\section{Microorganisms and Cultivation Conditions}

E. coli $\mathrm{DH} 5 \alpha$ strain was used as a host for cloning (Hanahan, 1985), S17-1 for transconjugation (Schäfer et al., 1994). Both strains were grown in lysogeny broth (LB) at $37{ }^{\circ} \mathrm{C}$ and supplemented with antibiotics $\left(50 \mu \mathrm{g} \mathrm{mL}^{-1}\right.$ kanamycin, 100 $\mu \mathrm{g} \mathrm{mL} L^{-1}$ spectinomycin, $10 \mu \mathrm{g} \mathrm{mL}{ }^{-1}$ tetracycline) when appropriate. C. glutamicum ATCC 13032 derived strains were cultivated in brain heart infusion with $0.5 \mathrm{M}$ sorbitol (BHIS), or CGXII minimal medium (Eggeling and Bott, 2004) supplemented with $1 \mathrm{mM}$ IPTG when appropriate. All bacterial strains and plasmids are listed in Tables 1, 2. For standard growth experiments in CGXII medium with C. glutamicum, overnight cultures in $10 \mathrm{~mL}$ BHIS were harvested and washed twice in TN-buffer ( $50 \mathrm{mM}$ Tris- $\mathrm{HCl}, 50 \mathrm{mM} \mathrm{NaCl}, \mathrm{pH}$ 6.3) before inoculation to an $\mathrm{OD}_{600}$ of 1 and supplementation with $40 \mathrm{~g} \mathrm{~L}^{-1}$ glucose as a sole carbon source. The cultivations in the BioLector microfermentation system (m2p-labs, Baesweiler, Germany) were performed in $3.2 \mathrm{~mL}$ FlowerPlates at $1,100 \mathrm{rpm}$ with a filling volume of $1,000 \mu \mathrm{L}$.

To test for the utilization of $\mathrm{L}-2 \mathrm{HG}$ as carbon source, $12 \mathrm{mM} \mathrm{L}-2 \mathrm{HG}$ and $10 \mathrm{mM}$ glucose were added, respectively, and the wildtype was inoculated to an initial $\mathrm{OD}_{600}$ of 0.5 . For optimization of the iron concentration in CGXII minimal medium the respective concentrations of iron-(II)-sulfate $(0-$ $3 \mathrm{mM}$ ) were supplemented. To test the inhibitory effect of glutarate on L-2HG production, 20 or $40 \mathrm{mM}$ of glutarate $(\mathrm{pH}$ 7.0) was added to CGXII medium, respectively.

For L-2HG production from wheat sidestream concentrate (WSC; obtained from Jäckering, Hamm, Germany) overnight cultures in $10 \mathrm{~mL}$ BHIS were harvested and washed twice in TN-buffer ( $50 \mathrm{mM}$ Tris-HCl, $50 \mathrm{mM} \mathrm{NaCl}, \mathrm{pH}$ 6.3) before inoculation to an $\mathrm{OD}_{600}$ of 1 . The medium consisted of $246 \mathrm{~g} \mathrm{~L}^{-1}$ WSC, $20 \mathrm{~g} \mathrm{~L}^{-1}$ ammonium sulfate as nitrogen source, $42 \mathrm{~g} \mathrm{~L}^{-1}$ MOPS as buffer and $2 \mathrm{mM}$ iron-(II)-sulfate (added as CsiD is an iron-containing enzyme). Growth in $10 \mathrm{~mL}$ Duetz microcultivation plates (Kuhner Shaker GmbH, Herzogenrath, Germany) was performed with different sandwich covers and culture volumes to alter the oxygen supply. Under "low oxygen" cultivation, cells were grown in $3 \mathrm{~mL}$ at $220 \mathrm{rpm}$ in an Ecotron ET25-TA-RC (Infors HT, Einsbach, Germany) and plate sandwich covers for low evaporation $(1.2 \mathrm{~mm}$ hole diameter) were used. For "high oxygen" supply the culture 
TABLE 1 | Bacterial strains used in this study.

\begin{tabular}{|c|c|c|}
\hline Strain & Relevant characteristics & References \\
\hline \multicolumn{3}{|l|}{ E. coli } \\
\hline $\mathrm{DH} 5 \alpha$ & slacU169 (ф80lacZ $\Delta \mathrm{M} 15)$, supE44, hsdR17, recA1, endA1, gyrA96, thi-1, relA1 & Hanahan, 1985 \\
\hline $\mathrm{S} 17-1$ & recA, pro, hsdR, RP4- 2Tc::Mu Km::Tn7 integrated into the chromosome & Simon et al., 1983 \\
\hline \multicolumn{3}{|l|}{ C. glutamicum } \\
\hline WT & C. glutamicum ATCC13032 & ATCC \\
\hline GRLys1 (DM1933دCGP123) & $\begin{array}{l}\text { C. glutamicum ATCC13032 with modifications: } \Delta p c k, p y c^{\mathrm{P} 458 \mathrm{~S}}, \text { hom }^{\mathrm{V} 59 \mathrm{~A}}, 2 \text { copies of } \\
\text { lys } C^{T 3111}, 2 \text { copies of asd, } 2 \text { copies of } d a p A, 2 \text { copies of dapB, } 2 \text { copies of } d d h, 2 \\
\text { copies of lysA, } 2 \text { copies of lysE, in-frame deletion of prophages CGP1 } \\
\text { (cg1507-cg1524), CGP2 (cg1746-cg1752) and CGP3 (cg1890-cg2071) }\end{array}$ & Unthan et al., 2015 \\
\hline GSLA2G & In-frame deletions of sugR, IdhA, snaA and cgmA, gdh in GRLys1 & Pérez-García et al., 2018 \\
\hline GluA & GSLA2G(pWWEx1-IdcC) (pEKEx3-patDA) (pEC-XT99A-gabTD*) & Pérez-García et al., 2018 \\
\hline GluA $\Delta s u c E$ & GSLA2G $\Delta s u c E(p V W E x 1-I d c C)$ (pEKEx3-patDA) (pEC-XT99A-gabTD*) & This study \\
\hline GluA2 & 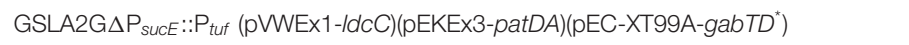 & This study \\
\hline HEGluA & GSLA2G(pWWEx1-ldcC-csiD Ec) (pEKEx3-patDA) (pEC-XT99A-gabTD*) & This study \\
\hline HBGluA & GSLA2G (pWWEx1-IdcC-csiD $\left.{ }^{H b}\right)$ (pEKEx3-patDA) (pEC-XT99A-gabTD*) & This study \\
\hline HPGluA & GSLA2G (pWWEx1-ldcC-csiD Pp)(pEKEx3-patDA)(pEC-XT99A-gabTD*) & This study \\
\hline HPGluA $\Delta$ sucE & GSLA2G $\Delta$ sucE (pWWEx1-IdcC-csiDPp) (pEKEx3-patDA) (pEC-XT99A-gabTD*) & This study \\
\hline HPGIuA2 & GSLA2G $\Delta P_{\text {SUCE }}:: P_{\text {tuf }}\left(p W W E x 1-I d c C-c s i D^{P p}\right)(p E K E x 3-p a t D A)\left(p E C-X T 99 A-g a b T D^{*}\right)$ & This study \\
\hline
\end{tabular}

TABLE 2 | Plasmids used in this study.

\begin{tabular}{|c|c|c|}
\hline Plasmid & Relevant characteristics & References \\
\hline pK19mobsacB & $\mathrm{Kan}^{\mathrm{R}}$, mobilizable E. coli vector mutagenesis (oriV, sacB) & Schäfer et al., 1994 \\
\hline pK19mobsacB- $\Delta s u c E$ & pK19mobsacB with a deletion construct sucE & This study \\
\hline pK19mobsacB- $\Delta \mathrm{P}_{\text {sucE }}:: \mathrm{P}_{\text {tuf }}$ & $\begin{array}{l}\text { pK19mobsacB with a promoter exchange of sucE with the strong } \\
\text { tuf-promoter and an optimized RBS }\end{array}$ & This study \\
\hline pWWEx1 & $\mathrm{Kan}^{\mathrm{R}}$, C. glutamicum/E. coli shuttle vector $\left(\mathrm{P}_{\mathrm{tac}}\right.$, lac $\left.^{q}\right)$ & $\begin{array}{l}\text { Peters-Wendisch et al., } \\
2001\end{array}$ \\
\hline pWWEX1-ldcC & pWWEx1 expressing IdcC from E.coli MG1655 & Pérez-García et al., 2018 \\
\hline pWWEx1-IdcC-csiD ${ }^{E c}$ & pWWEx1 expressing IdcC and csiD from E.coli MG1655 & This study \\
\hline pWWEx1-IdcC-csiD $D^{H b}$ & $\begin{array}{l}\text { pWWEx1 expressing IdcC from E.coli MG1655 and csiD from } \\
\text { Halobacillus sp. BA-2008 }\end{array}$ & This study \\
\hline pWWEx1-IdcC-csiD $P p$ & $\begin{array}{l}\text { pWWEx1 expressing IdcC from E.coli MG1655 and csiD from } \\
\text { Pseudomonas putida KT2440 }\end{array}$ & This study \\
\hline pEC-XT99A & Tet $^{R}$, C. glutamicum/E. coli shuttle vector $\left(P_{\text {trc }}\right.$, lacla,$p G A 1$, oriV $\left.{ }_{C g}\right)$ & Kirchner and Tauch, 2003 \\
\hline pEC-XT99A-gabTD* & $\begin{array}{l}\text { pEC-XT99A expressing gabT and gabD }{ }^{\mathrm{P} 134 \mathrm{~L}} \text { from } P \text {. stutzerii } \\
\text { ATCC17588 }\end{array}$ & This study \\
\hline pEKEx3 & Spec $^{R}$, C. glutamicum/E. coli shuttle vector $\left(\mathrm{P}_{\text {tac }}\right.$ lacla $\mathrm{pBL1}$, oriV $\left.{ }_{E C}\right)$ & Stansen et al., 2005 \\
\hline pEKEx3-patDA & pEKEx3, expressing patD and patA from E. coli MG1655 & Pérez-García et al., 2018 \\
\hline
\end{tabular}

$K m^{R}:$ kanamycin resistance.

Spec $^{R}$ : spectomycin resistance.

$T_{e} t^{R}$ : tetracycline resistance. 
TABLE 3 | Oligonucleotides used as primers in this study.

\begin{tabular}{|c|c|c|}
\hline Primer & Sequence $\left(5^{\prime}-3^{\prime}\right)$ & Description \\
\hline IdcC-fw & $\frac{\frac{\text { CCTGCAGGTCGACTCTAGAGG }}{\text { ATTCCGAAAGGAGGCCCTTCAG }}}{\text { ATGAACATCATTGCCATTATGGG }}$ & $\begin{array}{l}\text { Construction of } \\
\text { pWWEx1-ldcC- } \\
\text { csiD }\end{array}$ \\
\hline$I d c C-c s i D^{E c}-r v$ & $\begin{array}{l}\text { CCTITGTATTCTTGTATTGGCG } \\
\text { TITIATCCCGCCATITTAGG }\end{array}$ & \\
\hline$c s i D^{E c}-f w$ & $\begin{array}{l}\text { CCTAAAAATGGCGGGATAA } \\
\text { AAACGCCAATACAAGAAT } \\
\text { ACAAAAGGAGGTAATITT } \\
\text { ATGAATGCACTGACCGCCG }\end{array}$ & $\begin{array}{l}\text { Construction of } \\
\text { pWWEx1-ldcC- } \\
c s i D^{E C}\end{array}$ \\
\hline$c s i D^{E c}-r v$ & $\begin{array}{l}\text { GAATTCGAGCTCGGTACCCGGGGAT } \\
\text { CTTACTGATGCGTCTGGTAGT }\end{array}$ & \\
\hline$I d c C-c s i D^{P p}-r v$ & $\begin{array}{l}\text { GTCCTGTTAACAGGACTAATTAT } \\
\text { AATTATCCCGCCATIITAGG }\end{array}$ & \\
\hline $\mathrm{csiD}^{\mathrm{Pp}}$-fw & $\begin{array}{l}\text { CCTAAAAATGGCGGGATAA } \\
\text { TIATAATTAGTCCTGTIAACAG } \\
\text { GACATCAAAGGAGGTIIII } \\
\text { ATGAACGCCTITACGCAG }\end{array}$ & $\begin{array}{l}\text { Construction of } \\
\text { pWWEx1-ldcC- } \\
c s i D^{P p}\end{array}$ \\
\hline$c s i D^{P p}-r v$ & $\frac{\text { GAATTCGAGCTCGGTACCCGGGGATC }}{\text { TTATTGACCGCGCTGGTAC }}$ & \\
\hline $\mathrm{IdcC}-c s i D^{\mathrm{Hb}}-\mathrm{rv}$ & $\begin{array}{l}\text { ПTCCTITAAGTTATACTITCGTTAA } \\
\text { TIATCCCGCCATIITAGG }\end{array}$ & \\
\hline $\operatorname{csiD}^{\mathrm{Hb}}-\mathrm{fw}$ & $\begin{array}{l}\text { CCTAAAAATGGCGGGATAA } \\
\text { TTAACGAAAGTATA } \\
\text { ACTTAAAGGAACCACGTATाT } \\
\text { ATGTGCGCAGTAGAAATG }\end{array}$ & $\begin{array}{l}\text { Construction of } \\
\text { pWWEx1-ldcC- } \\
c s i D^{H b}\end{array}$ \\
\hline $\mathrm{csiD}^{\mathrm{Hb}}-\mathrm{rv}$ & $\begin{array}{l}\text { GAATTCGAGCTCGGTACCCGGGGATC } \\
\text { CTATTGAAGGAATCGTCC }\end{array}$ & \\
\hline IdcC-seq1 & TGAACGATGTAGTGCCAGTC & \\
\hline IdcC-seq2 & GCAATGGGATTATTGCGTGG & $\begin{array}{l}\text { Sequencing of } \\
\text { pWWEx1-ldcC- } \\
c s i D\end{array}$ \\
\hline IdcC-seq3 & CAGGCAGAATCGAAGTGA & \\
\hline $\operatorname{csiD}^{\mathrm{Ec}}$-seq & CCGATTACGTGCTGATG & $\begin{array}{l}\text { Sequencing of } \\
\text { pWWEx1-ldcC- } \\
c s i D^{E C}\end{array}$ \\
\hline $\mathrm{csiD}^{\mathrm{Pp}}$-seq & GATCTGGTTCACGAAC & $\begin{array}{l}\text { Sequencing of } \\
\text { pWWEx1-ldcC- } \\
c s i D^{P p}\end{array}$ \\
\hline $\mathrm{csiD}^{\mathrm{Hb}}$-seq & GTAGGTTCCATCAGTG & $\begin{array}{l}\text { Sequencing of } \\
\text { pWWEx1-ldcC- } \\
c S i D^{H b}\end{array}$ \\
\hline PSUcEA & $\begin{array}{l}\text { GCATGCCTGCAGGTCGACTCTAGA } \\
\text { GGCGTGACGTGTACAAGCGCG }\end{array}$ & \\
\hline PSUcEB & $\begin{array}{l}\text { TACGCGCCTACTGACACGCTAAAA } \\
\text { CTTAAGCCTCGCCCTTGCGTTC }\end{array}$ & $\begin{array}{l}\text { Construction of } \\
\text { pK19mobsacB } \\
\Delta \mathrm{P}_{\text {sucE }}:: \mathrm{P}_{\text {tuf }}\end{array}$ \\
\hline$P_{\text {tuf }}-f w$ & $\begin{array}{l}\text { GGCTGAACGCAAGGGCGAGGCTTAA } \\
\text { GTITAGCGTGTCAGTAGGC }\end{array}$ & \\
\hline$P_{\text {tuf }}-\mathrm{rV}$ & $\begin{array}{l}\text { AAGGAAGCTCAT } \\
\text { AAAAATACCTCCCCCAGTGTTCGTG } \\
\text { CCGTCGCCCCGGCGACGAGTTA } \\
\text { GTTACTGAATCCTAAGGGCA }\end{array}$ & \\
\hline PSUcEC & $\begin{array}{l}\text { CGGCACGAACACTGGGGGAGGTATTIT } \\
\text { ATGAGCTTCCTTGTAGAAAATC }\end{array}$ & \\
\hline PSUcED & $\begin{array}{l}\text { AATTCGAGCTCGGTACCCGGGGATC } \\
\text { GAATAACGATGAGCACACCG }\end{array}$ & \\
\hline
\end{tabular}

TABLE 3 | Continued

\begin{tabular}{|c|c|c|}
\hline Primer & Sequence $\left(5^{\prime}-3^{\prime}\right)$ & Description \\
\hline PSUcEE & GACTCGCTCACAAATGTGG & $\begin{array}{l}\text { Verification of } \\
\text { Promoter } \\
\text { exchange } \\
\Delta \mathrm{P}_{\text {sucE }}: \mathrm{P}_{\text {tuf }}\end{array}$ \\
\hline PSUcEF & GAATTGCTCACCGTCTCG & \\
\hline SucEA & $\begin{array}{l}\text { GCATGCCTGCAGGTCGACTCTAGAG } \\
\text { GTGGCACCTGGTGTTCCAG }\end{array}$ & \\
\hline SucEB & $\begin{array}{l}\text { TाTGGGCGGCCAGGATCTTIGCGAT } \\
\text { TTCTACAAGGAAGCTCAC }\end{array}$ & $\begin{array}{l}\text { Construction of } \\
\text { pK19mobsacB_ } \\
\text { AsucE }\end{array}$ \\
\hline SucEC & $\begin{array}{l}\text { GAATGGGTGAGCTTCCTTGTAGAA } \\
\text { ATCGCAAAGATCCTGGC }\end{array}$ & \\
\hline SucED & $\begin{array}{l}\text { AATTCGAGCTCGGTACCCGGGGATC } \\
\text { CGAATGGATTGGTCAGGG }\end{array}$ & \\
\hline SucEE & CTGCTGGTTGGGCTGTGG & $\begin{array}{l}\text { Verification sucE } \\
\text { deletion }\end{array}$ \\
\hline SucEF & GTTAATCATGAGGCGTCG & $\begin{array}{l}\text { Verification sucE } \\
\text { deletion }\end{array}$ \\
\hline
\end{tabular}

Overlaps to the vector are underlined, the ribosome binding site is indicated in italic and amino acid exchanges are shown in bold.

volume was decreased to $2 \mathrm{~mL}$ and standard plate sandwich covers ( $2.5 \mathrm{~mm}$ hole diameter) were used. Growth was monitored by determination of the $\mathrm{OD}_{600}$ with a V-1200 Spectrophotometer (VWR, Radnor, PA, USA).

\section{Molecular Biology Methods}

Genomic DNA of C. glutamicum, E. coli and P. putida were isolated as described previously (Eikmanns et al., 1994). The gene csiD from Halobacillus sp. BA-2008 was codonharmonized (Haupka, 2020) and synthesized with an optimized ribosomal binding site by Synbio Technologies (South Brunswick Township, New Jersey, United States of America). The standard molecular methods including plasmid isolation, molecular cloning and transformation of E. coli by heat shock and of C. glutamicum by electroporation with plasmid DNA were performed as described before (Eggeling and Bott, 2004). DNA sequences were amplified with the ALLin HiFi DNA Polymerase (HighQu, Kraichtal, Germany) using plasmid or genomic DNA as template. The oligonucleotides used in this study are listed in Table 3. The gene $l d c C$ was amplified from the vector pVWEx1-ldcC (Pérez-García et al., 2018), whereas the different $c s i D$ genes were amplified from genomic DNA of the respective organisms and assembled together into BamHI-digested pVWEx1 by Gibson Assembly, using the respective primers. The constructed plasmids were transferred into C. glutamicum by transformation. For deletion, plasmid pK19mobsacB (Schäfer et al., 1994), digested with BamHI was assembled with amplified DNA fragments flanking the gene sucE (cg2425) using Gibson Assembly and was transferred into E. coli S17-1 to follow a protocol for gene deletion routinely applied (Eggeling and Bott, 2004). For replacement of the native promoter by the stronger $t u f$-promoter, the tuf-promoter and the flanking regions of the promoter of sucE were amplified from 
genomic DNA of C. glutamicum and assembled with the digested plasmid pK19mobsacB. For higher expression rates the start codon of sucE was changed from GTG to ATG and an optimized ribosome binding site (RBS) was included (Salis, 2011).

\section{Coupled in vitro Activity of GabT and GabD}

The apparent activities of GABA transaminase GabT and succinate semialdehyde oxidoreductase GabD were assayed in combination by monitoring $\mathrm{NADPH}$ formation after the addition of 2-oxoglutarate. The preparation of the crude extract was carried out as previously described (Pérez-García et al., 2018). The $1 \mathrm{~mL}$ assay mix contained $150 \mathrm{mM}$ phosphate buffer ( $\mathrm{pH} 9.0)$, L-2HG $(2,4,8,12 \mathrm{mM})$ or $\mathrm{NaCl}$ as control,

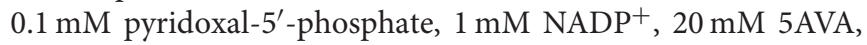
and $0.5 \mathrm{mg} \mathrm{mL}^{-1}$ crude extract. The reaction was started by the addition of $15 \mathrm{mM} 2$-oxoglutatarate. Protein concentrations were determined with the Bradford assay kit (Bio-Rad Laboratories, Hercules, CA, United States) using BSA (bovine serum albumin) as standard. The formation of NADPH was monitored photometrically at $340 \mathrm{~nm}$ and $30^{\circ} \mathrm{C}$ for 3 min using a Shimadzu UV-1202 spectrophotometer (Shimadzu, Duisburg, Germany).

\section{Quantification of Amino Acids, Diamines, and Carboxylic Acids}

The quantification of extracellular amino acids and their derivatives, carbohydrates and carboxylic acids in the cultivation medium was performed with a high-performance liquid chromatography system (1200 series, Agilent Technologies Deutschland $\mathrm{GmbH}$, Böblingen, Germany). After centrifugation of $1 \mathrm{~mL}$ of cell cultures at 14,000 rpm for 10 min the supernatant was stored at $-20^{\circ} \mathrm{C}$ prior to analysis. Analysis of L-lysine, 5AVA and the diamine cadaverine was performed by an automatic pre-column derivatization with ortho-phthaldialdehyde (OPA) and separated on a reversed phase HPLC using pre- and main column (LiChrospher 100 RP8 EC-5, $125 \times 4.6 \mathrm{~mm}$, CS Chromatographie Service $\mathrm{GmbH}$ ) with L-asparagine as internal standard (Schneider and Wendisch, 2010). Detection of the fluorescent derivatives was carried out with a fluorescence detector with an excitation wavelength of $230 \mathrm{~nm}$ and an emission wavelength of $450 \mathrm{~nm}$. Glutarate and L-2HG and glucose concentrations were measured with an amino exchange column (Aminex, $300 \times 8 \mathrm{~mm}, 10 \mu \mathrm{m}$ particle size, $25 \AA$ pore diameter, CS Chromatographie Service $\mathrm{GmbH}$ ) under isocratic conditions as described previously with a flow of $0.8 \mathrm{~mL} \mathrm{~min}-1$ (Schneider et al., 2011). The substances were detected with a refractive index detector (RID G1362A, 1200 series, Agilent Technologies) and a diode array detector (DAD G1315B, 1200 series, Agilent Technologies) at $210 \mathrm{~nm}$.

\section{Fermentative Production}

A baffled bioreactor with total a volume of $3.6 \mathrm{~L}$ was used (KLF, Bioengineering AG, Switzerland). Three six-bladed Rushton turbines were placed on the stirrer axis with a distance from the bottom of the reactor of 6,12 , and $18 \mathrm{~cm}$. The aspect ratio of the reactor was 2.6:1.0 and the stirrer to reactor diameter ratio was 0.39 . Automatic control of the stirrer speed between 400 and $1500 \mathrm{rpm}$ kept the relative dissolved oxygen saturation at $30 \%$.
A constant airflow of 1 or $2 \mathrm{NL} \min ^{-1}$ was maintained from the bottom through a sparger, corresponding to an aeration of 0.5 and $1 \mathrm{vvm}$, respectively.

The $\mathrm{pH}$ was kept constant at $7.0 \pm 0.1$ by automatic addition of phosphoric acid $[10 \%(v / v)]$ and potassium hydroxide $(4 \mathrm{M})$. The temperature was maintained at $30^{\circ} \mathrm{C}$. To prevent foaming $0.6 \mathrm{~mL} \mathrm{~L}^{-1}$ of the antifoam agent AF204 (Sigma Aldrich, Darmstadt, Germany) was added and a mechanical foam breaker was present to serve as an additional foam control. The fermentation was performed with a head space overpressure of 0.2 bar. The initial working volume of $2 \mathrm{~L}$ was inoculated to an $\mathrm{OD}_{600}$ of 1.5 from a shake flask pre-culture in CGXII minimal medium supplemented with $40 \mathrm{~g} \mathrm{~L}^{-1}$ glucose, $1 \mathrm{mM}$ IPTG and $2 \mathrm{mM} \mathrm{FeSO}_{4}$. Samples were collected by an autosampler and cooled down to $4^{\circ} \mathrm{C}$ until further use. The feed consisted only of $600 \mathrm{~g} \mathrm{~L}^{-1}$ glucose $\left(\rho=1.21 \mathrm{~kg} \mathrm{~m}^{-3}\right)$ and was started $4 \mathrm{~h}$ after the cells reached the late stationary phase, indicated by the $\mathrm{pO}_{2}$ rising above $80 \%$ again after the initial growth phase. The glucose feed was applied for $5 \mathrm{~min}$ with a flow of $1.2 \mathrm{~mL} \mathrm{~min}^{-1}$ when the $\mathrm{pO}_{2}$ surpassed $60 \%$. Further feed was only added, when the pO2 decreased to $30 \%$ after the addition of the feed solution to prevent oversaturation with glucose.

\section{RESULTS}

\section{Establishing de novo Biosynthesis of L-2HG by C. glutamicum}

As C. glutamicum can utilize some organic acids (Wendisch et al., 2016), the response of C. glutamicum WT to L-2HG was determined. When $\mathrm{L}-2 \mathrm{HG}$ was added to mineral salts medium as sole carbon source instead of glucose, no growth of $C$. glutamicum was observed. Moreover, when L-2HG plus glucose were assayed, C. glutamicum WT utilized glucose, but did not degrade L-2HG as revealed by HPLC analysis of the culture supernatants (data not shown). Thus, L-2HG does neither serve as sole nor as combined carbon source for C. glutamicum, which can be considered as a suitable host for production of L-2HG.

L-2HG is not a known metabolite of C. glutamicum, but it has been engineered for overproduction of glutarate (PérezGarcía et al., 2018). Inspection of the genome of C. glutamicum did not indicate the presence of a gene coding for an enzyme hydroxylating glutarate. In some bacteria like E. coli (Marschall et al., 1998; Knorr et al., 2018; Herr et al., 2019), P. putida, and Halobacillus sp. (Thompson et al., 2019), glutarate hydroxylase, also known as glutarate dioxygenase (EC 1.14.11.64), uses molecular oxygen to hydroxylate glutarate to L-2HG with concomitant decarboxylation of 2-oxoglutarate to succinate. Thus, the respective csiD genes from E. coli MG1655, P. putida KT2440 and Halobacillus sp. BA-2008 were overexpressed in synthetic operons with $l d c C$ from $E$. coli. The resulting pVWEx1plasmids were used to transform C. glutamicum GSLA2G (pEKEx3_patDA) (pEC-XT99A_gabTD*). The resulting strains were named HEGluA, HPGluA, and HBGluA, respectively. In production experiments, the three strains produced and secreted L-2HG. After 96 h C. glutamicum strain HEGluA accumulated $14 \pm 0 \mathrm{mM} \mathrm{L}-2 \mathrm{HG}$, strain HBGluA $7 \pm 1 \mathrm{mM} \mathrm{L}-2 \mathrm{HG}$, and 
strain HPGluA $22 \pm 2 \mathrm{mM} \mathrm{L-} 2 \mathrm{HG}$ (Figure 2). The strains showed comparable maximal growth rates of $0.13 \pm 0.00 \mathrm{~h}^{-1}$, but strain HPGluA showed a lag-phase of $24 \mathrm{~h}$. Taken together, a proof-of-principle for production of L-2HG by C. glutamicum was demonstrated.

\section{Role of the Succinate Exporter SucE in Export of Glutarate and L-2HG}

SucE is known to play a role in the export of the dicarboxylic acid succinate out of the C. glutamicum cell (Huhn et al.,

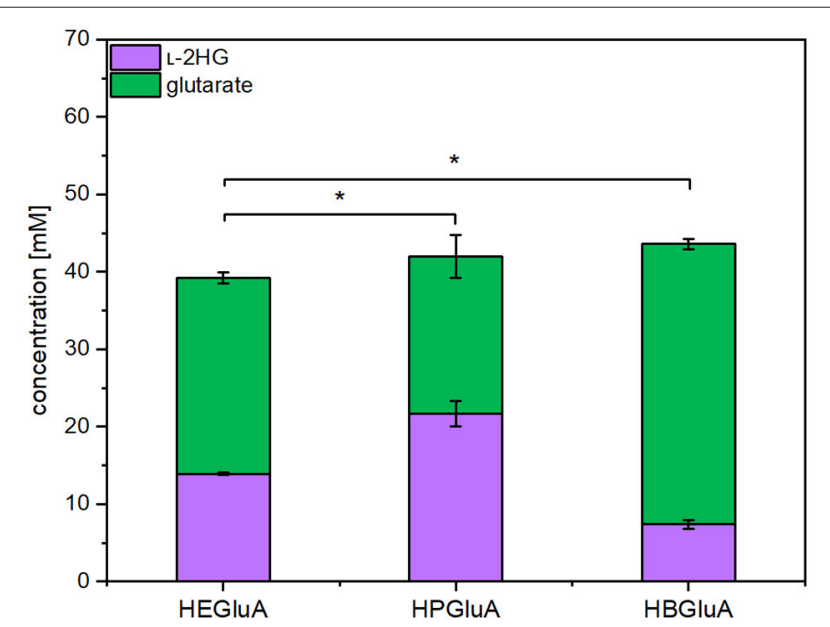

FIGURE 2 | Product titers of L-2HG and its precursor glutarate obtained with strains overproducing different glutarate hydroxylases. C. glutamicum strains HEGluA, HPGluA, and HBGluA expressing csiD from E. coli MG1655, P. putida KT2440, and Halobacillus sp. BA-2008, respectively, were grown in $40 \mathrm{~g} \mathrm{~L}^{-1}$ glucose CGXII minimal medium supplemented with $1 \mathrm{mM}$ IPTG in the microcultivation device BioLector. Values and error bars represent means and standard deviations from 3 replicate cultivations with supernatants analyzed after $96 \mathrm{~h}$. Statistical significance was assessed by Student's paired $t$-testing ( ${ }^{\star} p<0.05$, n.s, not significant).
2011). Since L-2HG and glutarate are also dicarboxylic acids, the role of SucE in the export of $\mathrm{L}-2 \mathrm{HG}$ and glutarate was studied. To this end, the $s u c E$ gene was either overexpressed by replacing the native promoter with the stronger $t u f$-promoter or deleted. The glutarate producing strain GluA2 that overexpressed sucE produced significantly more glutarate than the control strain GluA ( $44 \pm 0$ vs. $48 \pm 2 \mathrm{mM}$; Figure 3A). Similarly, upon overexpression of $s u c E$, production of L-2HG was slightly elevated $(24 \pm 0 \mathrm{mM}$ for HPGluA2 vs. $22 \pm 2 \mathrm{mM}$ for HPGluA; Figure 3A) as well as production of the by-product glutarate (26 $\pm 0 \mathrm{mM}$ for HPGluA2 vs. $20 \pm 3 \mathrm{mM}$ for HPGluA; Figure 3A). Thus, overexpression of $s u c E$ was beneficial for production of glutarate as well as L-2HG.

Deletion of sucE in glutarate producer GluA did not negatively affect glutarate production, however, growth was slowed $(0.12$ $\pm 0.00 \mathrm{~h}^{-1}$ for GluA vs. $0.07 \pm 0.00 \mathrm{~h}^{-1}$ for GluA $\Delta s u c E$; Figure 3B). Thus, SucE is not the main export system for glutarate and at least one other export system is able to compensate for the lack of SucE regarding glutarate export. Importantly, deletion of sucE reduced production of L-2HG more than 10 -fold $(2 \pm 0 \mathrm{mM}$ for HPGluA $\Delta s u c E$ vs. $26 \pm 1 \mathrm{mM}$ for HPGluA; Figure 3B), while the growth rate was not significantly impacted $\left(0.09 \pm 0.00 \mathrm{~h}^{-1}\right.$ for HPGluA vs. $0.08 \pm 0.01 \mathrm{~h}^{-1}$ for HPGluA $\triangle s u c E)$. The findings that $s u c E$ overexpression positively affected L-2HG production and that deletion of sucE dramatically reduced L-2HG production suggested that SucE may be active as export system for L-2HG.

\section{Enhanced Conversion of Glutarate to L-2HG by Increased Iron Concentrations}

As the glutarate hydroxylase $\mathrm{CsiD}$ is an $\mathrm{Fe}^{2+}$-dependent metalloenzyme (Herr et al., 2019; Thompson et al., 2019), the concentration of iron (II) in the media was varied and the effect on production of L-2HG determined. Concentrations of 0.5 to $3 \mathrm{mM} \mathrm{FeSO}_{4}$ were added on top of the standard concentration $(0.037 \mathrm{mM})$ in CGXII minimal medium
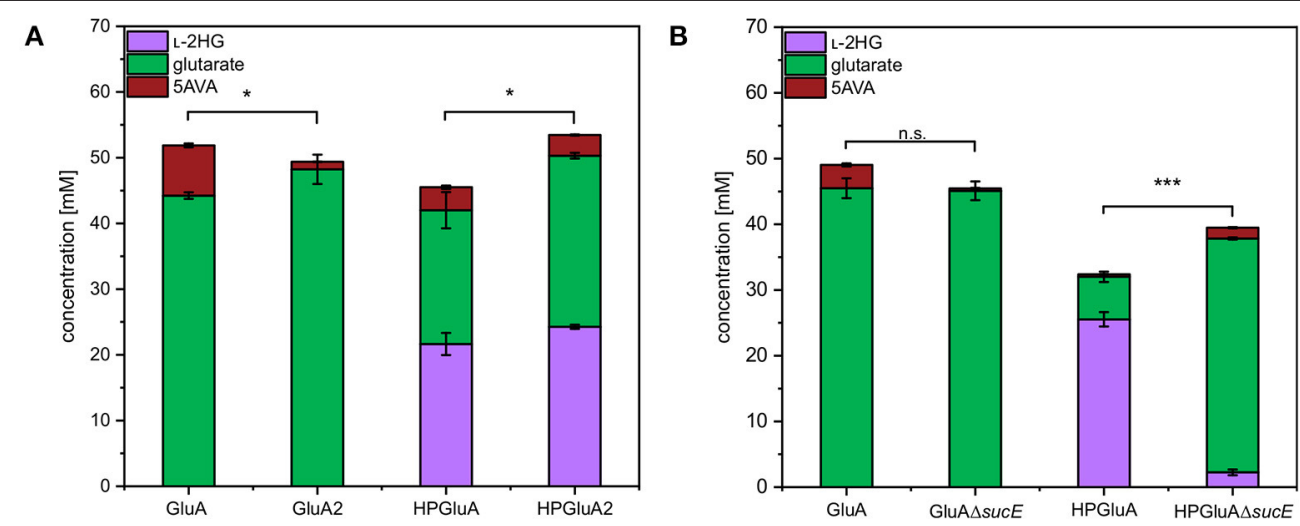

FIGURE 3 | Influence of overexpression and deletion of sucE on production of L-2HG, glutarate and 5AVA. (A) Strains GluA2 and HPGluA2 differed from strains GluA and HPGluA by overexpression of sucE. (B) Strains GluA $\Delta$ sucE and HPGluA $\Delta$ sucE were derived from strains GluA and HPGluA, respectively, by deletion of sucE. Strains were grown in the BioLector using $40 \mathrm{~g} \mathrm{~L}^{-1}$ glucose minimal medium supplemented with $1 \mathrm{mM} \mathrm{IPTG}$ and supernatants were analyzed after $120 \mathrm{~h}$. Values and error bars represent mean and standard deviation values ( $n=3$ cultivations). Statistical significance was assessed in Student's paired $t$-test $\left({ }^{\star \star \star} p<0.001,{ }^{\star} p<0.05\right.$, n.s. not significant). 


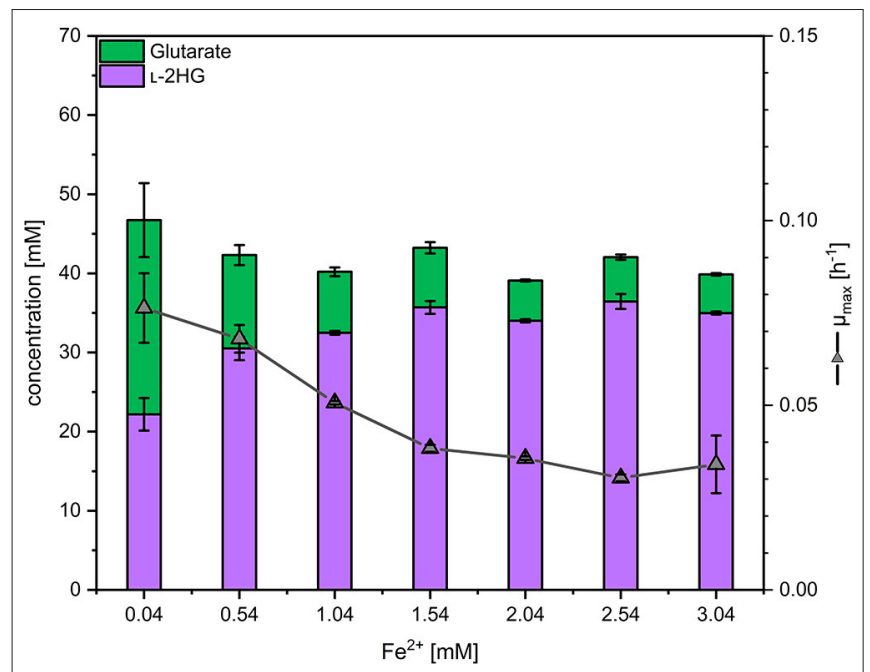

FIGURE 4 | Influence of the iron concentration on the maximal growth rate and production of L-2HG and glutarate. C. glutamicum HPGluA2 was grown in the BioLector with $40 \mathrm{~g} \mathrm{~L}^{-1}$ glucose minimal medium supplemented with $1 \mathrm{mM}$ IPTG and the indicated iron concentrations. Supernatants were analyzed after $96 \mathrm{~h}$. Values and error bars represent means and standard deviations ( $n=3$ cultivations).

(Eggeling and Bott, 2004). Three trends were observed: with increasing iron concentrations the growth rate and the formation of glutarate as by-product were reduced, while production of L-2HG was significantly increased (Figure 4). At an iron concentration of $2.04 \mathrm{mM}, 5 \pm 0 \mathrm{mM}$ glutarate and $34 \pm$ $0 \mathrm{mM} \mathrm{L}-2 \mathrm{HG}$ accumulated in the supernatant (Figure 4), thus, about $87 \%$ of glutarate were converted to L-2HG, while at the standard iron concentration L-2HG and glutarate accumulated to about equimolar concentrations. The growth inhibitory effect of elevated iron concentrations may be due to increased production of L-2HG and/or other effects elicited by higher iron concentrations. Thus, $2.04 \mathrm{mM}$ was choosen as the optimal iron concentration for further experiments to find the best compromise between L-2HG titer and volumetric productivity.

\section{Inhibitory Effects on Key Enzymes in L-2HG Pathway}

The finding that at higher iron concentrations less glutarate and more L-2HG accumulated, while the combined concentration of glutarate plus L-2HG was highest at the lowest iron concentration indicated bottlenecks. These may arise due to inhibition of glutarate hydroxylase CsiD by its product L-2HG (Knorr et al., 2018) and/or due to inhibition of enzymes of glutarate biosynthesis. The transaminases PatA from E. coli and GabT from $P$. stutzerii are crucial for glutarate biosynthesis (PérezGarcía et al., 2018) and some transaminases are known to be inhibited by L-2HG, which blocks binding of the substrate 2oxoglutarate (McBrayer et al., 2018). To approach this problem, enzyme activity assays were performed with crude extracts of C. glutamicum GluA. A combined activity assay of GABA transaminase GabT and succinate semialdehyde dehydrogenase
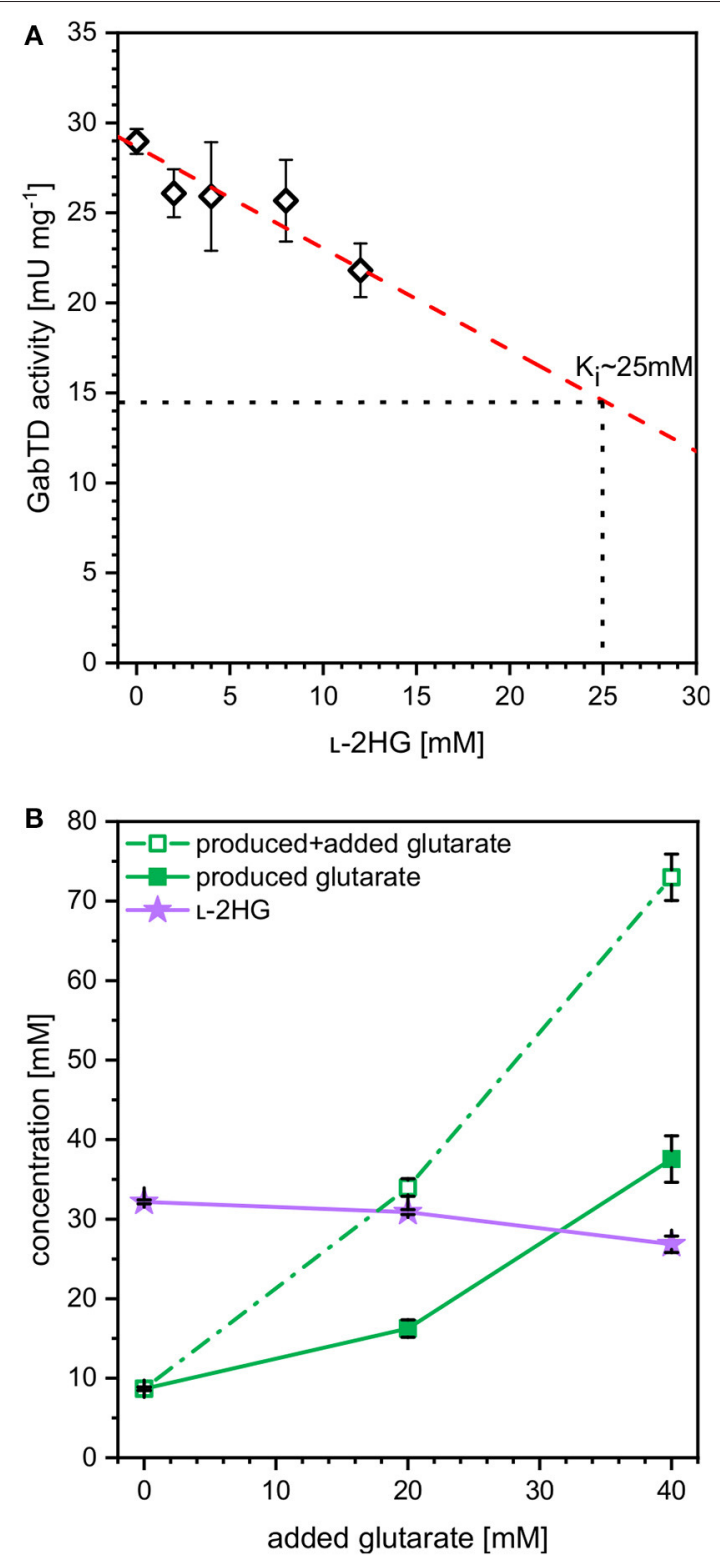

FIGURE 5 | Influence of L-2HG on the combined in vitro enzyme activities of GABA transaminase GabT and succinate semialdehyde dehydrogenase GabD (A) and influence of extracellularly added glutarate on production of L-2HG (B). (A) Crude extracts of GluA were assayed for combined in vitro enzyme activities of GABA transaminase GabT and succinate semialdehyde dehydrogenase GabD in the presence of increasing concentrations of L-2HG. (B) Strain HPGluA2 was cultivated in the BioLector with $40 \mathrm{~g} \mathrm{~L}^{-1}$ glucose minimal medium supplemented with $1 \mathrm{mM} \mathrm{IPTG}, 2 \mathrm{mM}$ iron (II)-sulfate and increasing concentrations of glutarate $(0,20,40 \mathrm{mM})$. Supernatant concentrations of L-2HG (filled violet triangles), glutarate (open green squares) as well as the net glutarate concentrations produced in addition to the added glutarate concentration (closed green squares) were determined after $96 \mathrm{~h}$ and are given as means and standard deviations of three independent cultivations.

GabD was performed as described previously (Pérez-García et al., 2018). In the presence of increasing concentrations of L$2 \mathrm{HG}(0-12 \mathrm{mM})$ the combined GabT and GabD activity was 
reduced. By extrapolation, it was determined that $25 \mathrm{mM} \mathrm{L-}$ $2 \mathrm{HG}$ resulted in half-maximal GabTD activity (Figure 5A). Thus, L-2HG negatively affects production of its precursor glutarate.

In order to determine if increased glutarate concentrations are beneficial for production of L-2HG, production of L-2HG was determined in the absence or presence of extracellularly added glutarate $(0,20$, or $40 \mathrm{mM})$. Notably, externally added glutarate slightly reduced production of L-2HG, whereas glutarate accumulation was increased (Figure 5B). When 0, 20 , or $40 \mathrm{mM}$ glutarate were added to the medium before inoculation, additional glutarate was produced: 9,16 , and $38 \mathrm{mM}$, respectively (Figure 5B). Thus, extracellular glutarate addition exerts a positive effect on glutarate production. The slight reduction of L-2HG production upon addition of extracellular glutarate may be due to substrate inhibition of glutarate hydroxylase CsiD.

\section{L-2HG Production at Bioreactor Scale}

In order to test if L-2HG production by strain HPGluA2 is stable at larger volumes, $2 \mathrm{~L}$ scale bioreactor fermentations were performed. Two aeration rates were tested: 0.5 and $1 \mathrm{vvm}$ (Figure 6). Under both conditions cells grew with similar growth rates (0.5 vvm: $\left.0.07 \mathrm{~h}^{-1}, 1 \mathrm{vvm:} 0.08 \mathrm{~h}^{-1}\right)$ and displayed a similar entry into the stationary phase after $56 \mathrm{~h}$. Oscillations in rDOS was due to overregulation of the stirrer, an often observed disadvantage of PID controllers, especially, when combined with the rDOS probes that are highly sensitive to fluctuations. However, almost 2-fold more biomass was formed at the higher aeration rate ( $\left.0.5 \mathrm{vvm:} 6.3 \mathrm{~g} \mathrm{~L}^{-1}, 1 \mathrm{vvm:} 9.9 \mathrm{~g} \mathrm{~L}^{-1}\right)$. Accumulation of the precursor glutarate was growth-coupled and ceased upon entry into the stationary phase (titers of around $10 \mathrm{mM}$ at 0.5 vvm and $13 \mathrm{mM}$ at $1 \mathrm{vvm}$ ), whereas production of L-2HG was delayed and started after $30 \mathrm{~h}$. While L-2HG production at an aeration rate of $0.5 \mathrm{vvm}$ reached the highest titer of $16 \mathrm{mM}$ at $120 \mathrm{~h}$ (Figure 6A), L-2HG production at an aeration rate of 1 vvm stopped at a titer of $6 \mathrm{mM}$ shortly after glucose was fully depleted (Figure 6B). Thus, the latter fermentation was switched to feeding mode to supply the culture with more carbon source. As consequence, the strain grew to a 2-fold higher biomass concentration of $16.3 \mathrm{~g} \mathrm{~L}^{-1}$ and produced fourfold more L-2HG reaching a titer of $24 \mathrm{mM}$ (Figure 6B).

Comparing the different cultivations in batch mode (Table 4) it becomes obvious that the L-2HG product yield showed an inverse relationship with the aeration rate, as its production was highest in the not actively aerated microcultivation system. Although HPGluA2 grew 2-fold slower in the microcultivation system, the volumetric productivity was higher than in the bioreactors (Table 4). By contrast, growth proceeded to the highest biomass concentration and the highest biomass yield was observed when aeration was highest (Table 4).

\section{L-2HG Production From Wheat Sidestream Concentrate}

Sustainable processes based on renewable feedstock are sought after. Therefore, it was tested if L-2HG can be produced from
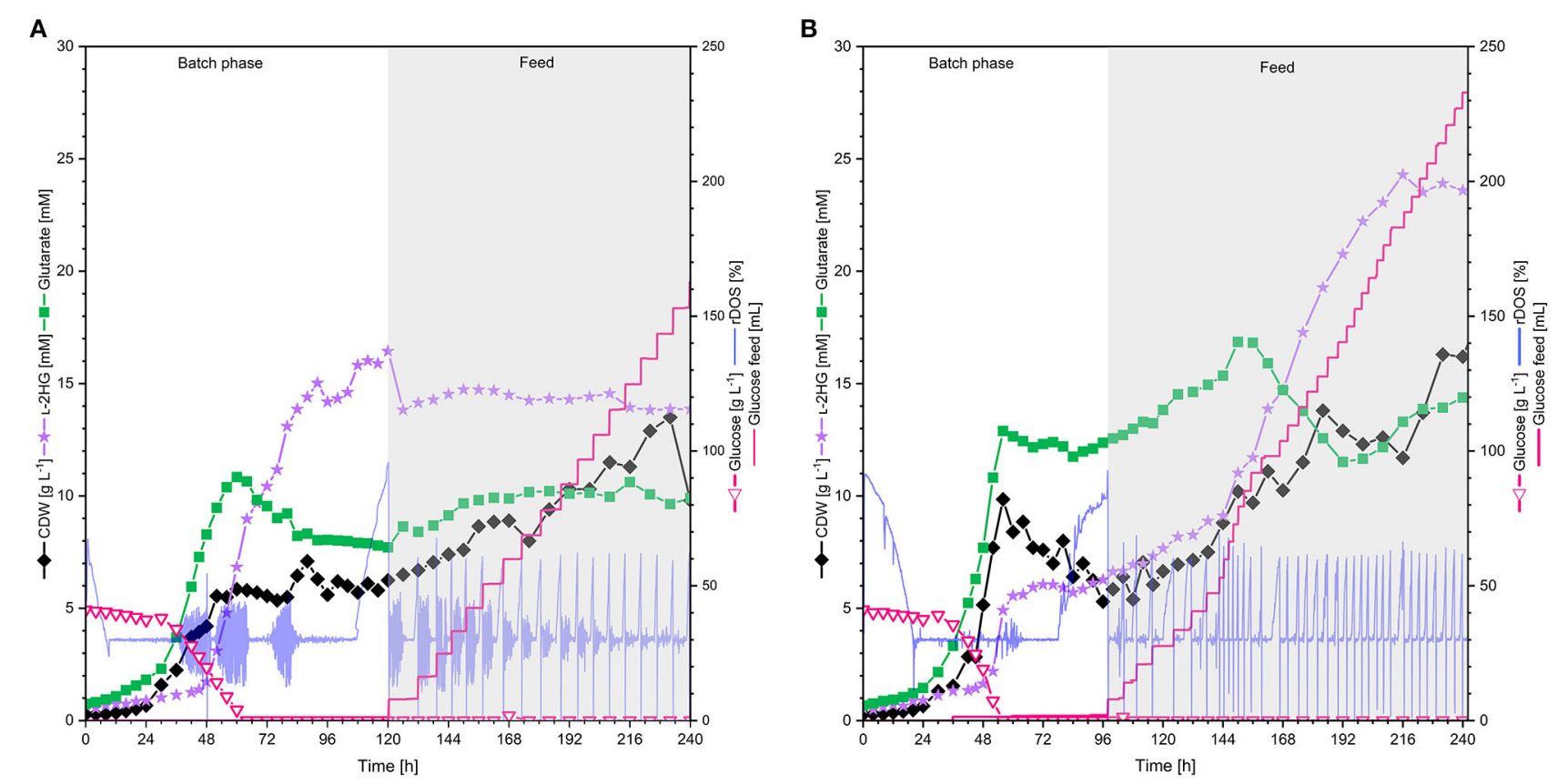

FIGURE 6 | L-2HG production by C. g/utamicum HPGluA2 in fed-batch fermentation with (A) 0.5 vvm and (B) 1 vvm aeration rate. HPGluA2 was cultivated in CGXII minimal medium in fed-batch mode over $240 \mathrm{~h}$, containing $40 \mathrm{~g} \mathrm{~L}^{-1}$ glucose and feeding $600 \mathrm{~g} \mathrm{~L}^{-1}$ glucose solution. $\mathrm{L}-2 \mathrm{HG}$ concentration is indicated in violet stars $(\mathrm{mM})$, biomass concentration $(\mathrm{CDW})$ is shown in black diamands $\left(\mathrm{g} \mathrm{L}^{-1}\right)$, glucose concentration $\left(\mathrm{g} \mathrm{L}^{-1}\right)$ is plotted as pink hollow triangles, and glutarate concentration $(\mathrm{mM})$ in green squares, $600 \mathrm{~g} \mathrm{~L}^{-1}$ glucose feed $(\mathrm{mL})$ is plotted as pink line and the relative dissolved oxygen saturation (rDOS) is indicated in light blue (\%). Cultivation was performed at $30^{\circ} \mathrm{C}$ and $\mathrm{pH} 7.0$ regulated with $10 \%(\mathrm{~V} / \mathrm{V}) \mathrm{H}_{3} \mathrm{PO}_{4}$ and $4 \mathrm{M} \mathrm{KOH}$. An overpressure of 0.2 bar was applied. $0.6 \mathrm{~mL} \mathrm{~L}^{-1}$ of antifoam agent $\mathrm{AF} 204$ (Sigma Aldrich, Taufkirchen, Germany) was added to the medium manually before inoculation. 
TABLE 4 | Comparison of L-2HG process parameters during different cultivation strategies.

\begin{tabular}{|c|c|c|c|c|c|c|c|c|}
\hline System & Mode/Phase & $\begin{array}{c}\text { Aeration } \\
\text { rate } \\
\text { [vvm] }\end{array}$ & $\begin{array}{l}\mu_{\max } \\
{\left[\mathrm{h}^{-1}\right]}\end{array}$ & $\begin{array}{c}\mathrm{CDW} \\
{\left[\mathrm{g} \mathrm{L}^{-1}\right]}\end{array}$ & $\begin{array}{c}\text { Titer } \\
{\left[\mathrm{g} \mathrm{L}^{-1}\right]}\end{array}$ & $\begin{array}{c}Y_{X / S} \\
{\left[g^{-1}\right]}\end{array}$ & $\begin{array}{c}Y_{\mathrm{P} / \mathrm{S}} \\
{\left[\mathrm{g} \mathrm{g}^{-1}\right]}\end{array}$ & $\begin{array}{c}\text { VP } \\
{\left[\mathrm{g} \mathrm{L}^{-1} \mathrm{~h}^{-1}\right]}\end{array}$ \\
\hline \multirow[t]{2}{*}{ Bioreactor } & Batch & 0.5 & 0.07 & 6.3 & 2.4 & 0.16 & 0.06 & 0.02 \\
\hline & Batch & 1 & 0.08 & 9.9 & 0.9 & 0.25 & 0.02 & 0.01 \\
\hline
\end{tabular}

$\mu_{\max }$, maximal growth rate; $C D W$, cell dry weight; $Y_{X / S}$, biomass yield; $Y_{P / S}$, product yield; VP, volumetric productivity.

A

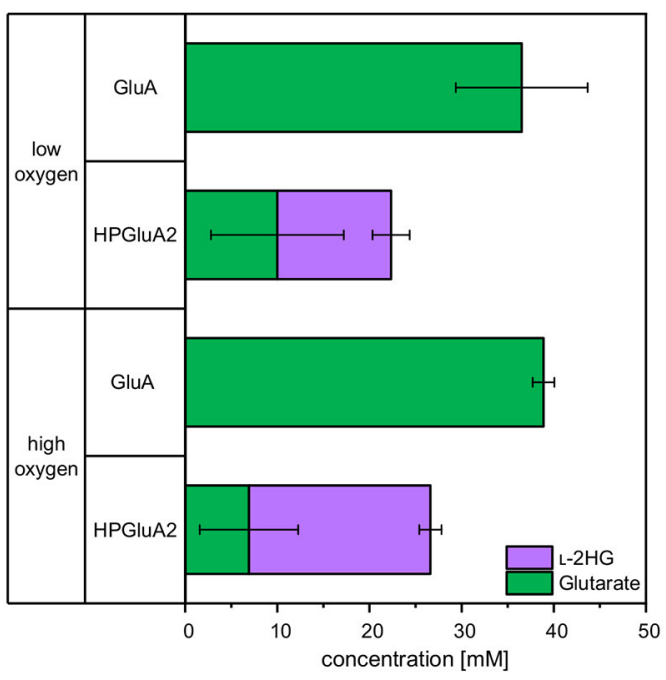

B

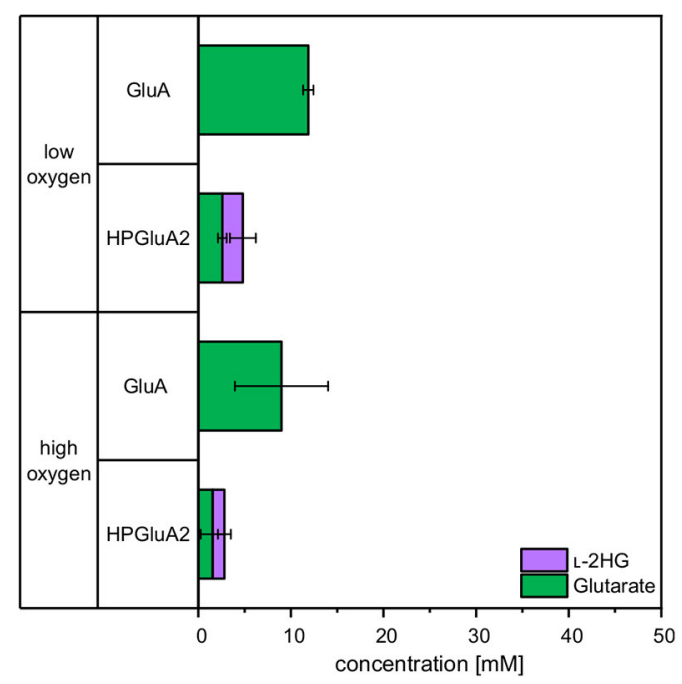

FIGURE 7 | Comparison of glutarate and L-2HG production based on glucose (A) or wheat sidestream concentrate (B). C. glutamicum glutarate producer GluA and L-2HG producer HPGluA2 were grown in the Duetz microcultivation plates with low or high oxygen supply using covers of different air permeability and different volumes ( 3 and $2 \mathrm{~mL}$ ). Strains were cultivated in CGXII minimal medium with $40 \mathrm{~g} \mathrm{~L}^{-1}$ glucose or with a mixture containing $246 \mathrm{~g} \mathrm{~L}^{-1}$ WSC, $20 \mathrm{~g} \mathrm{~L}-1$ ammonium sulfate and $42 \mathrm{~g} \mathrm{~L}^{-1}$ MOPS. Both media were supplemented with $1 \mathrm{mM} \mathrm{IPTG}$ and $2 \mathrm{mM} \mathrm{FeSO}_{4}$. Supernatants were analyzed after $96 \mathrm{~h}$. Values and error bars represent means and standard deviations of 3 cultivations.

a sidestream of industrial starch production (wheat sidestream concentrate; WSC). WSC contains hardly any starch, but various sugars like glucose, fructose, sucrose, raffinose, xylose and arabinose (D’Appolonia and Rayas-Duarte, 1994). Production of glutarate from WSC was also analyzed. To this end, $C$. glutamicum strains GluA and HPGluA2 were cultivated for $96 \mathrm{~h}$ either in CGXII medium with glucose or in WSC medium. Aeration was altered by different cultivation volumes and by using either "low oxygen" or "high oxygen" Duetz plates. For HPGluA2 both media were supplemented with $2 \mathrm{mM}$ $\mathrm{FeSO}_{4}$. Glucose-based glutarate production by strain GluA was comparable for both aeration schemes (37 \pm 7 and $39 \pm$ $1 \mathrm{mM}$; Figure 7), whereas it was lower in WSC medium (12 \pm 1 and $9 \pm 5 \mathrm{mM}$ of glutarate under high and low oxygen supply, respectively; Figure 7). HPLC analysis of WSC using a refractive index detector did not allow to identify all peaks, but we could show that around $12 \mathrm{mM}$ glucose and $6 \mathrm{mM}$ maltose were utilized (data not shown) and $3 \pm 0 \mathrm{mM}$ glutarate and $2 \pm 1 \mathrm{mM}$ L-2HG accumulated under low oxygen conditions.
No significant differences with respect to L-2HG production by strain HPGluA2 with different oxygen supply were observed (Figure 7). Albeit leading to lower titers, production of L$2 \mathrm{HG}$ to concentrations around $2 \mathrm{mM}$ were achieved. Thus, L$2 \mathrm{HG}$ production from the renewable feedstock wheat sidestream concentrate was demonstrated.

\section{DISCUSSION}

In this study, production of the sought after compound L-2HG by the industrial workhorse C. glutamicum was demonstrated after extension of lysine biosynthesis in a six-step cascade employing the metalloenzyme CsiD from $P$. putida as final step. The glucose-based process was stable in $2 \mathrm{~L}$ bioreactor cultivations and a $\mathrm{L}-2 \mathrm{HG}$ titer of $3.5 \mathrm{~g} \mathrm{~L}^{-1}$ was obtained in fed-batch fermentation. Moreover, L-2HG production based on the renewable feedstock wheat sidestream concentrate was demonstrated. 
L-2HG production was achieved by glutarate hydroxylase extending lysine biosynthesis in a six-step cascade, in which only the last committed step catalyzed by oxygen-dependent glutarate hydroxylase requires oxygen. Glutarate hydroxylases belong to the large family of non-heme $\mathrm{Fe}(\mathrm{II})$ - and 2oxoglutarate-dependendent oxygenases, which are essential for diverse biological functions. These enzymes form an Fe(IV)oxo intermediate to initiate oxidative transformations and can be assigned to four major types of reactions: hydroxylation, halogenation, ring formation and desaturation (Hausinger, 2004). The glutarate hydroxylases which have been studied in this research belong to the enzymes catalyzing a hydroxylation reaction at an unactivated carbon center by incorporation of molecular oxygen (Guengerich, 2015; Martinez and Hausinger, 2015). The CsiD enzymes from E. coli MG1655 and P. putida KT2440 have been recently characterized in different studies displaying their high specificities toward the native substrate glutarate with $\mathrm{K}_{\mathrm{M}}$-values around $0.65 \mathrm{mM}$ in E. coli (Knorr et al., 2018) and around $0.15 \mathrm{mM}$ for P. putida (Zhang et al., 2018). The $\mathrm{K}_{\mathrm{M}}$-values of around $0.1 \mathrm{mM}$ for the co-substrate 2-oxoglutarate are comparable for both enzymes. The higher affinity of glutarate hydroxylase from $P$. putida for glutarate is reflected by the better conversion of glutarate to L-2HG observed in this study. Even though no $\mathrm{K}_{\mathrm{M}}$ value for the glutarate hydroxylase from Halobacillus sp. BA-2008 has been determined yet, it was demonstrated that it converts $5 \mathrm{mM}$ glutarate to L-2HG with comparable efficiency to the other tested hydroxylases with 2-oxoglutarate as co-substrate (Thompson et al., 2019). Although the capability of CsiD from Halobacillus sp. BA-2008 to produce L-2HG from glutarate was demonstrated in C. glutamicum, the efficiency of the codon harmonized version of CsiD was inferior compared to the enzymes derived from other organisms.

It could be demonstrated that L-2HG inhibits the combined GabTD activity with an inhibitory constant of about $25 \mathrm{mM}$ (Figure 5A). Due to its structural similarity to 2-OG, L-2HG potentially inhibits transamination reactions (McBrayer et al., 2018) by competitive inhibition (Intlekofer et al., 2015). Here, possibly competitive inhibition of 2-OG dependent transaminase GabT by L-2HG may have limited L-2HG product titers. Potentially, this may be overcome by enzyme engineering of the 2-OG binding pocket of GabT for better differentiation of this substrate from L-2HG. We have chosen enzymes GabT and GabD from $P$. stutzeri as they performed better than those from C. glutamicum, $P$. putida and P. syringae regarding glutarate production (Pérez-García et al., 2018). Since we did not compare GabT and GabD enzymes from various sources for inhibition of their activities by L-2HG, identifying feedback resistant enzymes/variants of the GabT and GabD enzymes in future work may help to increase L-2HG production. On the other hand, glutarate hydroxylase CsiD is subject to weak product inhibition (Knorr et al., 2018). Therefore, CsiD from other sources or variants may be selected that exhibit no or reduced product inhibition in order to improve L-2HG production.

Moreover, a weak substrate inhibition on L-2HG production by glutarate could also be identified (Figure 5B). CsiD from E. coli was recently characterized and the reaction mechanism was described (Knorr et al., 2018; Herr et al., 2019). Since the substrate analogon $\mathrm{N}$-oxalylglycine (NOG), a 2-OG mimic, inhibited CsiD (Knorr et al., 2018), this feedback inhibition may limit L-2HG production. However, since we did not assay feedback inhibition of various glutarate hydroxylases by L-2HG, future work to improve L-2HG production should involve the identification of feedback resistant CsiD enzymes/variants.

Surprisingly, extracellular addition of glutarate boosted glutarate production. This is unlikely due to effects on enzyme activities. C. glutamicum possesses chromosomal copies of gabT and gabD (Pérez-García et al., 2018; Haupka et al., 2020). The PucR-like regulator GabR that requires GABA as coactivator activates transcription of the gabTDP operon (Zhu et al., 2020). Possibly, glutarate mimics GABA as coactivator of GabR activating the endogenous gabTDP operon and increasing GabT and GabD enzyme levels in addition to plasmid-borne expression of gabT and gabD from $P$. stutzeri.

Cultivation schemes with higher oxygen supply reduced L-2HG production, but improved growth to high biomass concentrations. Glutarate hydroxylases are 2-OG-dependent enzymes and these metalloenzymes specifically require $\mathrm{Fe}^{2+}$ as cofactor for their function (Mitchell et al., 2017; Dunham et al., 2018). Previously, it has been shown that increased iron concentrations improve enzyme activity (Fukumori and Hausinger, 1993). Increased $\mathrm{Fe}^{2+}$ concentrations improved L$2 \mathrm{HG}$ product titers, but slowed growth significantly. This might be due to iron effects such as toxicity mainly due to the formation of hydroxyl radicals as oxidative stress response (Braun, 1997; Touati, 2000; Eid et al., 2017) and/or due to inhibition of 2-OG-dependent dioxygenases and methylases, which play an essential role in DNA/RNA repair (van den Born et al., 2009), by L-2HG (Low et al., 2001; Ledesma-García et al., 2016). Provision of oxygen and iron to the C. glutamicum cell are interlinked. Molecular oxygen is required for 2-OGdependent dioxygenases such as CsiD to form the Fe(IV)-oxo intermediate, but with too much oxygen decoupling occurs via "non-productive reactions" resulting in inactive Fe(III)containing enzymes (Hausinger, 2004) as observed with AlkB (Henshaw et al., 2004) and TfdA (Liu et al., 2001). Secondly, an "uncoupled turnover" of the co-substrate 2-OG may occur by decomposition of 2-OG to carbon dioxide and succinate. These "uncoupled reactions" might contribute to the lower titers of $\mathrm{L}-2 \mathrm{HG}$ obtained in $2 \mathrm{~L}$ scale fermentative production with the highest oxygen supply. The addition of ascorbic acid is a promising option since ascorbate improved hydroxylase activity (Fukumori and Hausinger, 1993). Alternatively, production of L-2HG may be improved by concomitant overproduction of either glutathione (Liu et al., 2019) or ascorbate in C. glutamicum.

Our results suggested that export of L-2HG involves SucE (Figure 3). Surprisingly, glutarate export does not depend solely on SucE. Overexpression of sucE increased succinate production (Zhu et al., 2014) similar to increased production of glutarate and L-2HG observed here. Deletion of sucE revealed that SucE is the main export system for L-2HG, but not for glutarate. Production of L-2HG may benefit from re-uptake of glutarate secreted to the culture medium as by-product. However, the uptake system for glutarate is unknown. MctC is involved in the uptake of pyruvate, 
propionate, and acetate, but it is not clear if it accepts glutarate (Jolkver et al., 2009).

Glutarate was observed as significant by-product. Unlike L$2 \mathrm{HG}$, which likely is exported by SucE (s. above), glutarate is exported by YnfM (Fukui et al., 2019). Overexpression of ynfM improved production of glutarate, succinate, and 2-OG (Fukui et al., 2019; Han et al., 2020). Thus, deletion of $y n f M$ is a suitable strategy to abolish export of glutarate as by-product of L-2HG production.

Alternative feedstocks are important to achieve sustainable biotechnological processes. In this respect, sidestreams are highly relevant. Glycerol is a sidestream of the biodiesel process and glycerol accumulates as stoichiometric by-product. C. glutamicum has been engineered to produce amino acids from pure and technical grade glycerol (Rittmann et al., 2008; Meiswinkel et al., 2013b). Access to nitrogenous sidestreams from the fishery industry such as glucosamine or $\mathrm{N}$-acetylglucosamine is important if the target product is containing nitrogen atoms (Matano et al., 2014, 2016). For products lacking nitrogen atoms, access to lignocellulosics is pivotal (Gopinath et al., 2011; Buschke et al., 2013; Meiswinkel et al., 2013a; Hadiati et al., 2014; Matsuura et al., 2019). The focus of this study was a sidestream of industrial starch production. Although production was lower compared to glucose (30\% for glutarate, $15 \%$ for $\mathrm{L}-2 \mathrm{HG}$ ), media composition was easy and required only a buffer, a nitrogen source for growth and iron for glutarate hydroxylase. We envision improved production of $\mathrm{L}-2 \mathrm{HG}$ from wheat sidestream concentrate once access to sugars other than the native substrates glucose, fructose, maltose, and sucrose is achieved, e.g., to raffinose, xylose and arabinose, that are present in this feedstock (D'Appolonia and RayasDuarte, 1994). Strategies for access to the lignocellulosic pentoses xylose and arabinose have been established (Kawaguchi et al., 2008; Gopinath et al., 2011; Schneider et al., 2011; Meiswinkel et al., 2013a; Imao et al., 2017) and may prove useful for improved production of L-2HG from the alternative feedstock wheat sidestream concentrate. In this respect, provision of iron and/or iron chelators may prove essential as shown here for CsiD function.

The approach described here may be followed for production of the stereoisomer D-2HG. To this end, the glutarate pathway described here has to be extended with enzymes for conversion of glutarate to D-2HG. These enzymes may be sourced from lysine degrading bacteria as $\mathrm{D}-2 \mathrm{HG}$ occurs as intermediate in some of these pathways, e.g., in E. coli (Zhao and Winkler, 1996) and different Pseudomonaceace (Zhang et al., 2017; Guo et al., 2018; Thompson et al., 2019). Future work will reveal if this approach is suitable for fermentative production of $\mathrm{D}-2 \mathrm{HG}$.

\section{REFERENCES}

Adkins, J., Jordan, J., and Nielsen, D. R. (2013). Engineering Escherichia coli for renewable production of the 5-carbon polyamide buildingblocks 5-aminovalerate and glutarate. Biotechnol. Bioeng. 110, 1726-1734. doi: 10.1002/bit.24828

Braun, V. (1997). Avoidance of iron toxicity through regulation of bacterial iron transport. Biol. Chem. 378, 779-786.

Buschke, N., Becker, J., Schäfer, R., Kiefer, P., Biedendieck, R., and Wittmann, C. (2013). Systems metabolic engineering of xylose-utilizing Corynebacterium

\section{DATA AVAILABILITY STATEMENT}

The original contributions presented in the study are included in the article/supplementary material, further inquiries can be directed to the corresponding author/s.

\section{AUTHOR'S NOTE}

VFW wishes to dedicate this article in memoriam of scientific and personal friend Michael M. Goodin, Professor of Plant Pathology, University of Kentucky, Lexington, KY.

\section{AUTHOR CONTRIBUTIONS}

CP and VFW conceived and designed the experiments. CP constructed plasmids and strains, cultivated, and analyzed C. glutamicum strains and prepared a draft of the manuscript. $\mathrm{CP}$ and FM performed bioreactor experiments and evaluated data. $A B$ conducted the growth experiment on wheat sidestream concentrate. CP, AB, FM, and VFW finalized the manuscript. VFW acquired funding and coordinated the study. All authors read and approved the final version of the manuscript.

\section{FUNDING}

This research was funded in part by the European Regional Development Fund (ERDF) and the Ministry of Economic Affairs, Innovation, Digitalization, and Energy of the State of North Rhine-Westphalia and $\mathrm{CP}, \mathrm{AB}$, and VFW acknowledge support by grant Cluster Industrial Biotechnology (CLIB) Kompetenzzentrum Biotechnologie (CKB) (34.EFRE0300095/1703FI04) and FM and VFW by grant Bicomer (EFRE-0400184). Support for the Article Processing Charge by the Deutsche Forschungsgemeinschaft and the Open Access Publication Fund of Bielefeld University is acknowledged. The funding bodies had no role in the design of the study or the collection, analysis, or interpretation of data or in writing the manuscript.

\section{ACKNOWLEDGMENTS}

We thank Dr. T. Roick and M. Andreae from Jäckering Mühlenund Nährmittelwerke GmbH, Hamm, Germany, for providing wheat sidestream concentrate. Moreover, we thank Dr. Joe Risse and Dipl.-Ing. Thomas Schäffer from Fermentation Technology, Technical Faculty \& CeBiTec, University of Bielefeld, for technical assistance and kind advice. We additionally thank Anastasia Kerbs for scientific discussion.

glutamicum for production of 1,5-diaminopentane. Biotechnol. J. 8, 557-570. doi: 10.1002/biot.201200367

Cheng, J., Luo, Q., Duan, H., Peng, H., Zhang, Y., Hu, J., et al. Efficient whole-cell catalysis for 5-aminovalerate production from L-lysine by using engineered Escherichia coli with ethanol pretreatment. Sci Rep. (2020) 10, 990. doi: 10.1038/s41598-020-57752-x

Chowdhury, R., Yeoh, K. K., Tian, Y., Hillringhaus, L., Bagg, E. A., Rose, N. R., et al. (2011). The oncometabolite 2-hydroxyglutarate inhibits histone lysine demethylases. EMBO Rep. 12, 463-469. doi: 10.1038/embor.2 011.43 
D’Appolonia, B. L., and Rayas-Duarte, P. (1994). "Wheat carbohydrates: structure and functionality," in Wheat: Production, Properties and Quality, eds W. Bushuk, and V. F. Rasper (Boston, MA: Springer), 107-127. doi: $10.1007 / 978-1-4615-2672-8 \_8$

Dunham, N. P., Chang, W., Mitchell, A. J., Martinie, R. J., Zhang, B., Bergman, J. A., et al. (2018). Two distinct mechanisms for $\mathrm{C}-\mathrm{C}$ desaturation by iron(II)- and 2(Oxo)glutarate-dependent oxygenases: importance of $\alpha$-heteroatom assistance. J. Am. Chem. Soc. 140, 7116-7126. doi: 10.1021/jacs.8b01933

Eggeling, L., and Bott, M. (2004). Handbook of Corynebacterium glutamicum, 1st Edn. Bota Raton, FL: CRC Press; LLC.

Eid, R., Arab, N. T. T., and Greenwood, M. T. (2017). Iron mediated toxicity and programmed cell death: a review and a re-examination of existing paradigms. Biochim. Biophys. Acta Mol. Cell Res. 1864, 399-430. doi: 10.1016/j.bbamcr.2016.12.002

Eikmanns, B. J., Thum-Schmitz, N., Eggeling, L., Lüdtke, K. U., and Sahm, H. (1994). Nucleotide sequence, expression and transcriptional analysis of the Corynebacterium glutamicum gltA gene encoding citrate synthase. Microbiology 140, 1817-1828. doi: 10.1099/13500872-140-8-1817

Fukui, K., Nanatani, K., Nakayama, M., Hara, Y., Tokura, M., and Abe, K. (2019). Corynebacterium glutamicum CgynfM encodes a dicarboxylate transporter applicable to succinate production. J. Biosci. Bioeng. 127, 465-471. doi: 10.1016/j.jbiosc.2018.10.004

Fukumori, F., and Hausinger, R. P. (1993). Purification and characterization of 2,4dichlorophenoxyacetate/alpha-ketoglutarate dioxygenase. J. Biol. Chem. 268, 24311-24317.

Gopinath, V., Meiswinkel, T. M., Wendisch, V. F., and Nampoothiri, K. M. (2011). Amino acid production from rice straw and wheat bran hydrolysates by recombinant pentose-utilizing Corynebacterium glutamicum. Appl. Microbiol. Biotechnol. 92, 985-996. doi: 10.1007/s00253-011-3478-x

Guengerich, F. P. (2015). Introduction: metals in biology: $\alpha$ ketoglutarate/iron-dependent dioxygenases. J. Biol. Chem. 290, 20700-20701. doi: 10.1074/jbc.R115.675652

Guo, X., Zhang, M., Cao, M., Zhang, W., Kang, Z., Xu, P., et al. (2018). d-2Hydroxyglutarate dehydrogenase plays a dual role in L-serine biosynthesis and d-malate utilization in the bacterium Pseudomonas stutzeri. J. Biol. Chem. 293, 15513-15523. doi: 10.1074/jbc.RA118.003897

Hadiati, A., Krahn, I., Lindner, S. N., and Wendisch, V. F. (2014). Engineering of Corynebacterium glutamicum for growth and production of L-ornithine, L-lysine, and lycopene from hexuronic acids. Bioresour. Bioprocess. 1:25. doi: 10.1186/s40643-014-0025-5

Han, T., Kim, G. B., and Lee, S. Y. (2020). Glutaric acid production by systems metabolic engineering of an L-lysine-overproducing Corynebacterium glutamicum. Proc. Natl. Sci. U.S.A.117, 30328-30334. doi: 10.1073/pnas.2017483117

Hanahan, D. (1985). Techniques for transformation of E. coli. DNA Cloning A Practical Approach 1, 109-135.

Haupka, C. (2020). Chaupka/Codon_Harmonization: Release v1.2.0. doi: 10.5281/zenodo.4062177

Haupka, C., Delépine, B., Irla, M., Heux, S., and Wendisch, V. F. (2020). Flux enforcement for fermentative production of 5 -aminovalerate and glutarate by Corynebacterium glutamicum. Catalysts 10:1065. doi: 10.3390/catal10091065

Hausinger, R. P. (2004). $\quad \mathrm{Fe}(\mathrm{II}) / \alpha$-ketoglutarate-dependent hydroxylases and related enzymes. Crit. Rev. Biochem. Mol. Biol. 39, 21-68. doi: $10.1080 / 10409230490440541$

Henshaw, T. F., Feig, M., and Hausinger, R. P. (2004). Aberrant activity of the DNA repair enzyme AlkB. J. Inorg. Biochem. 98, 856-861. doi: 10.1016/j.jinorgbio.2003.10.021

Herr, C. Q., Macomber, L., Kalliri, E., and Hausinger, R. P. (2019). Glutarate L-2-hydroxylase (CsiD/GlaH) is an archetype $\mathrm{Fe}(\mathrm{II}) / 2$-oxoglutaratedependent dioxygenase. Adv. Protein Chem. Struct. Biol. 117, 63-90. doi: 10.1016/bs.apcsb.2019.05.001

Hibi, M., and Ogawa, J. (2014). Characteristics and biotechnology applications of aliphatic amino acid hydroxylases belonging to the $\mathrm{Fe}(\mathrm{II}) / \alpha$-ketoglutaratedependent dioxygenase superfamily. Appl. Microbiol. Biotechnol. 98, 3869-3876. doi: 10.1007/s00253-014-5620-z

Hüdig, M., Maier, A., Scherrers, I., Seidel, L., Jansen, E. E. W., Mettler-Altmann, T., et al. (2015). Plants possess a cyclic mitochondrial metabolic pathway similar to the mammalian metabolic repair mechanism involving malate dehydrogenase and L-2-hydroxyglutarate dehydrogenase. Plant Cell Physiol. 56, 1820-1830. doi: $10.1093 / p c p / p c v 108$
Huhn, S., Jolkver, E., Krämer, R., and Marin, K. (2011). Identification of the membrane protein SucE and its role in succinate transport in Corynebacterium glutamicum. Appl. Microbiol. Biotechnol. 89, 327-335. doi: 10.1007/s00253-010-2855-1

Imao, K., Konishi, R., Kishida, M., Hirata, Y., Segawa, S., Adachi, N., et al. (2017). 1,5-Diaminopentane production from xylooligosaccharides using metabolically engineered Corynebacterium glutamicum displaying beta-xylosidase on the cell surface. Bioresour. Technol. 245, 1684-1691. doi: 10.1016/j.biortech.2017.05.135

Intlekofer, A. M., Dematteo, R. G., Venneti, S., Finley, L. W. S., Lu, C., Judkins, A. R., et al. (2015). Hypoxia induces production of L-2-hydroxyglutarate. Cell Metab. 22, 304-311. doi: 10.1016/j.cmet.2015.06.023

Intlekofer, A. M., Wang, B., Liu, H., Shah, H., Carmona-Fontaine, C., Rustenburg, A. S., et al. (2017). L-2-Hydroxyglutarate production arises from noncanonical enzyme function at acidic pH. Nat. Chem. Biol. 13, 494-500. doi: $10.1038 /$ nchembio. 2307

Jolkver, E., Emer, D., Ballan, S., Krämer, R., Eikmanns, B. J., and Marin, K. (2009). Identification and characterization of a bacterial transport system for the uptake of pyruvate, propionate, and acetate in Corynebacterium glutamicum. J. Bacteriol. Res. 191, 940-948. doi: 10.1128/JB.01155-08

Jorge, J. M. P., Pérez-García, F., and Wendisch, V. F. (2017). A new metabolic route for the fermentative production of 5-aminovalerate from glucose and alternative carbon sources. Bioresour. Technol. 245, 1701-1709. doi: 10.1016/j.biortech.2017.04.108

Kawaguchi, H., Sasaki, M., Vertès, A. A., Inui, M., and Yukawa, H. (2008). Engineering of an L-arabinose metabolic pathway in Corynebacterium glutamicum. Appl. Microbiol. Biotechnol. 77, 1053-1062. doi: $10.1007 / \mathrm{s} 00253-007-1244-\mathrm{x}$

Kirchner, O., and Tauch, A. (2003). Tools for genetic engineering in the amino acid-producing bacterium Corynebacterium glutamicum. J. Biotechnol. 104, 287-299. doi: 10.1016/S0168-1656(03)00148-2

Knorr, S., Sinn, M., Galetskiy, D., Williams, R. M., Wang, C., Müller, N., et al. (2018). Widespread bacterial lysine degradation proceeding via glutarate and L-2-hydroxyglutarate. Nat. Commun. 9:5071. doi: 10.1038/s41467-018-07563-6

Ledesma-García, L., Sánchez-Azqueta, A., Medina, M., Reyes-Ramírez, F., and Santero, E. (2016). Redox proteins of hydroxylating bacterial dioxygenases establish a regulatory cascade that prevents gratuitous induction of tetralin biodegradation genes. Sci. Rep. 6:23848. doi: 10.1038/srep23848

Liu, A., Ho, R. Y. N., Que, L., Ryle, M. J., Phinney, B. S., and Hausinger, R. P. (2001). Alternative reactivity of an $\alpha$-ketoglutarate-dependent iron(II) oxygenase: enzyme self-hydroxylation. J. Am. Chem. Soc. 123, 5126-5127. doi: $10.1021 /$ ja005879x

Liu, W., Zhu, X., Lian, J., Huang, L., and Xu, Z. (2019). Efficient production of glutathione with multi-pathway engineering in Corynebacterium glutamicum. J. Ind. Microbiol. Biotechnol. 46, 1685-1695. doi: 10.1007/s10295-019-02220-3

Low, D. A., Weyand, N. J., and Mahan, M. J. (2001). Roles of DNA adenine methylation in regulating bacterial gene expression and virulence. Infect. Immun. 69, 7197-7204. doi: 10.1128/IAI.69.12.7197-7204.2001

Marschall, C., Labrousse, V., Kreimer, M., Weichart, D., Kolb, A., and HenggeAronis, R. (1998). Molecular analysis of the regulation of $c s i D$, a carbon starvation-inducible gene in Escherichia coli that is exclusively dependent on $\sigma S$ and requires activation by cAMP-CRP. J. Mol. Biol. 276, 339-353. doi: 10.1006/jmbi.1997.1533

Martinez, S., and Hausinger, R. P. (2015). Catalytic mechanisms of $\mathrm{Fe}(\mathrm{II})-$ and 2-oxoglutarate-dependent oxygenases. J. Biol. Chem. 290, 20702-20711. doi: $10.1074 / \mathrm{jbc}$.R115.648691

Matano, C., Kolkenbrock, S., Hamer, S. N., Sgobba, E., Moerschbacher, B. M., and Wendisch, V. F. (2016). Corynebacterium glutamicum

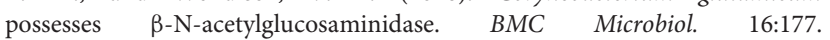
doi: 10.1186/s12866-016-0795-3

Matano, C., Uhde, A., Youn, J.-W., Maeda, T., Clermont, L., Marin, K., et al. (2014). Engineering of Corynebacterium glutamicum for growth and L-lysine and lycopene production from $\mathrm{N}$-acetyl-glucosamine. Appl. Microbiol. Biotechnol. 98, 5633-5643. doi: 10.1007/s00253-014-5676-9

Matsuura, R., Kishida, M., Konishi, R., Hirata, Y., Adachi, N., Segawa, S., et al. (2019). Metabolic engineering to improve 1,5-diaminopentane production from cellobiose using $\beta$-glucosidase-secreting Corynebacterium glutamicum. Biotechnol. Bioeng. 116, 2640-2651. doi: 10.1002/bit.27082

McBrayer, S. K., Mayers, J. R., DiNatale, G. J., Shi, D. D., Khanal, J., Chakraborty, A. A., et al. (2018). Transaminase inhibition by 2-hydroxyglutarate impairs 
glutamate biosynthesis and redox homeostasis in glioma. Cell 175, 101-116.e25. doi: 10.1016/j.cell.2018.08.038

Meiswinkel, T. M., Gopinath, V., Lindner, S. N., Nampoothiri, K. M., and Wendisch, V. F. (2013a). Accelerated pentose utilization by Corynebacterium glutamicum for accelerated production of lysine, glutamate, ornithine and putrescine. Microb. Biotechnol. 6, 131-140. doi: 10.1111/1751-7915.12001

Meiswinkel, T. M., Rittmann, D., Lindner, S. N., and Wendisch, V. F. (2013b). Crude glycerol-based production of amino acids and putrescine by Corynebacterium glutamicum. Bioresour. Technol. 145, 254-258. doi: $10.1016 /$ j.biortech.2013.02.053

Metzner, M., Germer, J., and Hengge, R. (2004). Multiple stress signal integration in the regulation of the complex $\sigma$ S-dependent csiDygaF-gabDTP operon in Escherichia coli. Mol. Microbiol. 51, 799-811. doi: $10.1046 / j .1365-2958.2003 .03867 . x$

Mitchell, A. J., Dunham, N. P., Martinie, R. J., Bergman, J. A., Pollock, C. J., $\mathrm{Hu}, \mathrm{K}$., et al. (2017). Visualizing the reaction cycle in an iron(II)- and 2(oxo)-glutarate-dependent hydroxylase. J. Am. Chem. Soc. 139, 13830-13836. doi: $10.1021 /$ jacs.7b07374

Nan, A., and Feher, I. C. (2017). A new polyester based on allyl $\alpha$-hydroxy glutarate as shell for magnetite nanoparticles. AIP Conf. Proc. 1917:040003. doi: $10.1063 / 1.5018285$

Navarro, E., Subirana, J. A., and Puiggali, J. (1997). The structure of nylon 12,5 is characterized by two hydrogen bond directions as are other polyamides derived from glutaric acid. Polymer 38, 3429-3432. doi: 10.1016/S0032-3861(97)00017-7

Oldham, W. M., Clish, C. B., Yang, Y., and Loscalzo, J. (2015). Hypoxiamediated increases in L-2-hydroxyglutarate coordinate the metabolic response to reductive stress. Cell Metab. 22, 291-303. doi: 10.1016/j.cmet.2015.06.021

Pan, B.-C., Chen, W.-H., Lee, T.-M., and Liou, G.-S. (2018). Synthesis and characterization of novel electrochromic devices derived from redoxactive polyamide-TiO2 hybrids. J. Mater. Chem. C 6, 12422-12428. doi: $10.1039 / \mathrm{C} 8 \mathrm{TC} 04469 \mathrm{D}$

Pérez-García, F., Jorge, J. M. P., Dreyszas, A., Risse, J. M., and Wendisch, V. F. (2018). Efficient production of the dicarboxylic acid glutarate by Corynebacterium glutamicum via a novel synthetic pathway. Front. Microbiol. 9:2589. doi: 10.3389/fmicb.2018.02589

Peters-Wendisch, P., Schiel, B., Wendisch, V. F., Katsoulidis, E., Möckel, B., Sahm, H., et al. (2001). Pyruvate carboxylase is a major bottleneck for glutamate and lysine production by Corynebacterium glutamicum. J. Mol. Microbiol. Biotechnol. 3, 295-300. Available online at: https://www.caister.com/backlist/ $\mathrm{jmmb} / \mathrm{v} / \mathrm{v} 3 / \mathrm{v} 3 \mathrm{n} 2 / 22 . \mathrm{pdf}$

Rittmann, D., Lindner, S. N., and Wendisch, V. F. (2008). Engineering of a glycerol utilization pathway for amino acid production by Corynebacterium glutamicum. Appl. Environ. Microbiol. 74, 6216-6222. doi: 10.1128/AEM.00963-08

Rzem, R., Veiga-da-Cunha, M., Noel, G., Goffette, S., Nassogne, M.-C., Tabarki, B., et al. (2004). A gene encoding a putative FAD-dependent L-2-hydroxyglutarate dehydrogenase is mutated in L-2-hydroxyglutaric aciduria. Proc. Natl. Acad. Sci. U.S.A. 101, 16849-16854. doi: 10.1073/pnas. 0404840101

Salis, H. M. (2011). "Chapter two - the ribosome binding site calculator," in Methods in Enzymology Synthetic Biology, Part B, ed C. Voigt (Cambridge, MA: Academic Press), 19-42. doi: 10.1016/B978-0-12-385120-8.00002-4

Schäfer, A., Tauch, A., Jäger, W., Kalinowski, J., Thierbach, G., and Pühler, A. (1994). Small mobilizable multi-purpose cloning vectors derived from the Escherichia coli plasmids pK18 and pK19: selection of defined deletions in the chromosome of Corynebacterium glutamicum. Gene 145, 69-73. doi: 10.1016/0378-1119(94)90324-7

Schneider, J., Niermann, K., and Wendisch, V. F. (2011). Production of the amino acids L-glutamate, L-glutamate, L-lysine, L-ornithine and L-arginine from arabinose by recombinant Corynebacterium glutamicum. J. Biotechnol. 154, 191-198. doi: 10.1016/j.jbiotec.2010.07.009

Schneider, J., and Wendisch, V. F. (2010). Putrescine production by engineered Corynebacterium glutamicum. Appl. Microbiol. Biotechnol. 88, 859-868. doi: 10.1007/s00253-010-2778-x

Shelar, S., Shim, E.-H., Brinkley, G. J., Kundu, A., Carobbio, F., Poston, T., et al. (2018). Biochemical and epigenetic insights into L-2-hydroxyglutarate, a potential therapeutic target in renal cancer. Clin. Cancer Res. 24, 6433-6446. doi: 10.1158/1078-0432.CCR-18-1727

Shim, E.-H., Livi, C. B., Rakheja, D., Tan, J., Benson, D., Parekh, V., et al. (2014). L-2-Hydroxyglutarate: an epigenetic modifier and putative oncometabolite in renal cancer. Cancer Discov. 4, 1290-1298. doi: 10.1158/2159-8290.CD-13-0696
Simon, R., Priefer, U., and Pühler, A. (1983). A broad host range mobilization system for in vivo genetic engineering: transposon mutagenesis in gram negative bacteria. Bio/Technology 1, 784-791. doi: 10.1038/nbt1183-784

Stansen, C., Uy, D., Delaunay, S., Eggeling, L., Goergen, J. L., and Wendisch, V. F. (2005). Characterization of a Corynebacterium glutamicum lactate utilization operon induced during temperature-triggered glutamate production. Appl. Environ. Microbiol. 71, 5920-5928. doi: 10.1128/AEM.71.10.5920-5928.2005

Thompson, M. G., Blake-Hedges, J. M., Cruz-Morales, P., Barajas, J. F., Curran, S. C., Eiben, C. B., et al. (2019). Massively parallel fitness profiling reveals multiple novel enzymes in Pseudomonas putida lysine metabolism. mBio 10:e02577-18. doi: 10.1128/mBio.02577-18

Touati, D. (2000). Iron and oxidative stress in bacteria. Arch. Biochem. Biophys. 373, 1-6. doi: 10.1006/abbi.1999.1518

Unthan, S., Baumgart, M., Radek, A., Herbst, M., Siebert, D., Brühl, N., et al. (2015). Chassis organism from Corynebacterium glutamicum-a top-down approach to identify and delete irrelevant gene clusters. Biotechnol. J. 10, 290-301. doi: 10.1002/biot.201400041

van den Born, E., Bekkelund, A., Moen, M. N., Omelchenko, M. V., Klungland, A., and Falnes, P. Ø. (2009). Bioinformatics and functional analysis define four distinct groups of AlkB DNA-dioxygenases in bacteria. Nucleic. Acids Res. 37, 7124-7136. doi: 10.1093/nar/gkp774

Varela, O., and Orgueira, H. A. (2000). "Synthesis of chiral polyamides from carbohydrate-derived monomers," in Advances in Carbohydrate Chemistry and Biochemistry, ed D. Horton (Cambridge, MA: Academic Press), 137-174. doi: 10.1016/S0065-2318(00)55005-7

Wanders, R. J. A., Vilarinho, L., Hartung, H. P., Hoffmann, G. F., Mooijer, P. A. W., Jansen, G. A., et al. (1997). L-2-hydroxyglutaric aciduria: normal L2-hydroxyglutarate dehydrogenase activity in liver from two new patients. J. Inherit. Metab. Dis. 20, 725-726. doi: 10.1023/A:1005355316599

Wendisch, V. F., Brito, L. F., Gil Lopez, M., Hennig, G., Pfeifenschneider, J., Sgobba, E., et al. (2016). The flexible feedstock concept in industrial biotechnology: metabolic engineering of Escherichia coli, Corynebacterium glutamicum, Pseudomonas, Bacillus and yeast strains for access to alternative carbon sources. J. Biotechnol. 234, 139-157. doi: 10.1016/j.jbiotec.2016.07.022

Xu, W., Yang, H., Liu, Y., Yang, Y., Wang, P., Kim, S.-H., et al. (2011). Oncometabolite 2-hydroxyglutarate is a competitive inhibitor of $\alpha$-ketoglutarate-dependent dioxygenases. Cancer Cell 19, 17-30. doi: 10.1016/j.ccr.2010.12.014

Zhang, M., Gao, C., Guo, X., Guo, S., Kang, Z., Xiao, D., et al. (2018). Increased glutarate production by blocking the glutaryl-CoA dehydrogenation pathway and a catabolic pathway involving L-2-hydroxyglutarate. Nat. Commun. 9:2114. doi: 10.1038/s41467-018-04513-0

Zhang, W., Zhang, M., Gao, C., Zhang, Y., Ge, Y., Guo, S., et al. (2017). Coupling between d-3-phosphoglycerate dehydrogenase and d-2hydroxyglutarate dehydrogenase drives bacterial L-serine synthesis. Proc. Natl. Acad. Sci. U.S.A. 114, E7574-E7582. doi: 10.1073/pnas.1619034114

Zhao, G., and Winkler, M. E. (1996). A novel alpha-ketoglutarate reductase activity of the serA-encoded 3-phosphoglycerate dehydrogenase of Escherichia coli $\mathrm{K}-12$ and its possible implications for human 2-hydroxyglutaric aciduria. $J$. Bacteriol. 178, 232-239. doi: 10.1128/JB.178.1.232-239.1996

Zhu, L., Mack, C., Wirtz, A., Kranz, A., Polen, T., Baumgart, M., et al. (2020). Regulation of $\gamma$-aminobutyrate (GABA) utilization in Corynebacterium glutamicum by the PucR-type transcriptional regulator GabR and by alternative nitrogen and carbon sources. Front. Microbiol. 11:544045. doi: $10.3389 /$ fmicb. 2020.544045

Zhu, N., Xia, H., Yang, J., Zhao, X., and Chen, T. (2014). Improved succinate production in Corynebacterium glutamicum by engineering glyoxylate pathway and succinate export system. Biotechnol. Lett. 36, 553-560. doi: $10.1007 / \mathrm{s} 10529-013-1376-2$

Conflict of Interest: The authors declare that the research was conducted in the absence of any commercial or financial relationships that could be construed as a potential conflict of interest.

Copyright $\odot 2021$ Prell, Burgardt, Meyer and Wendisch. This is an open-access article distributed under the terms of the Creative Commons Attribution License (CC $B Y)$. The use, distribution or reproduction in other forums is permitted, provided the original author(s) and the copyright owner(s) are credited and that the original publication in this journal is cited, in accordance with accepted academic practice. No use, distribution or reproduction is permitted which does not comply with these terms. 